\title{
Manipulating electron redistribution to achieve exotic electronic pyroelectricity in dynamic [FeCo] crystals
}

\author{
Pritam Sadhukhan
}

Kyushu University

Shu-Qi Wu

Kyushu University https://orcid.org/0000-0003-4148-6409

Jeremy Long

Kyushu University

Takumi Nakanishi

Kyushu University

\section{Shinji Kanegawa}

Kyushu University

\section{Kaige Gao}

Kyushu University

Kaoru Yamamoto

Okayama University of Science

\section{Hajime Okajima}

Aoyama Gakuin University https://orcid.org/0000-0002-5269-0598

\section{Akira Sakamoto}

Aoyama Gakuin University https://orcid.org/0000-0002-4646-1318

\section{Michael Baker}

University of Manchester https://orcid.org/0000-0002-8246-3177

Thomas Kroll

SLAC National Accelerator Laboratory

\section{Dimosthenis Sokaras}

SLAC National Accelerator Laboratory

\section{Atsushi Okazawa}

University of Tokyo

Norimichi Kojima

University of Tokyo

\section{Yoshihito Shiota}

Kyushu University https://orcid.org/0000-0003-2054-9845 
Kyushu University

Osamu Sato ( $\sim$ sato@cm.kyushu-u.ac.jp)

Kyushu University

\section{Article}

Keywords: pyroelectricity, magnetic materials and devices, electronic devices

Posted Date: February 23rd, 2021

DOl: https://doi.org/10.21203/rs.3.rs-241749/v1

License: (c) (i) This work is licensed under a Creative Commons Attribution 4.0 International License. Read Full License

Version of Record: A version of this preprint was published at Nature Communications on August 10th, 2021. See the published version at https://doi.org/10.1038/s41467-021-25041-4. 


\section{Manipulating electron redistribution to achieve exotic electronic pyroelectricity in dynamic $[\mathrm{FeCo}]$ crystals}

Pritam Sadhukhan ${ }^{1, \#}$, Shu-Qi $\mathrm{Wu}^{1, \#}$, Jeremy Ian Long ${ }^{1}$, Takumi Nakanishi ${ }^{1}$, Shinji Kanegawa ${ }^{1, *}$,

Kaige $\mathrm{Gao}^{2}$, Kaoru Yamamoto ${ }^{3}$, Hajime Okajima ${ }^{4}$, Akira Sakamoto ${ }^{4}$, Michael L. Baker ${ }^{5,6}$, Thomas Kroll $^{7}$, Dimosthenis Sokaras ${ }^{7}$, Atsushi Okazawa ${ }^{8}$, Norimichi Kojima ${ }^{9}$, Yoshihito Shiota ${ }^{1}$, Kazunari Yoshizawa $^{1}$, and Osamu Sato ${ }^{1, *}$

${ }^{1}$ Institute for Materials Chemistry and Engineering \& IRCCS, Kyushu University, 744 Motooka, Nishiku, Fukuoka 819-0395, Japan.

${ }^{2}$ College of Physical Science and Technology, Yangzhou University, Jiangsu 225009, P. R. China.

${ }^{3}$ Department of Applied Physics, Okayama University of Science, Okayama 700-0005, Japan

${ }^{4}$ Graduate School of Science and Engineering, Aoyama Gakuin University, 5-10-1 Fuchinobe, Chuoku, Sagamihara, Kanagawa 252-5258, Japan.

${ }^{5}$ The Department of Chemistry, The University of Manchester, Manchester M13 9PL, UK.

${ }^{6}$ The Department of Chemistry, The University of Manchester at Harwell, Didcot OX11 0FA, UK.

${ }^{7}$ Stanford Synchrotron Radiation Lightsource, SLAC National Accelerator Laboratory, Stanford University, Menlo Park, California 94025, United States.

${ }^{8}$ Division of Chemistry, Institution of Liberal Education, Nihon University School of Medicine, 30-1 Oyaguchi Kamimachi, Itabashi-ku, Tokyo 173-8610, Japan.

${ }^{9}$ Department of Basic Science, Graduation School of Arts and Sciences, The University of Tokyo, 3-81 Komaba, Meguro-ku, Tokyo 153-8902, Japan.

${ }^{\#}$ P.S. and S.-Q.W. contributed equally.

Correspondence and requests for materials should be addressed to S. K. (email: kanegawa@,cm.kyushuu.ac.jp) or to O. S. (email: sato@cm.kyushu-u.ac.jp). 


\section{Abstract}

Pyroelectricity plays a crucial role in modern sensors and energy conversion devices. However, obtaining materials with large and nearly constant pyroelectric coefficients over a wide temperature range for the practical uses remains a formidable challenge, because in conventional ferroelectric materials the pyroelectric effect promptly declines upon cooling from the transition temperature. Attempting to discover a solution to this obstacle, we combined molecular design of labile electronic structure with the crystal engineering of the molecular orientation in lattice resulting in the electronic pyroelectricity of purely molecular origin. Here, we report a polar crystal of an [FeCo] dinuclear complex exhibiting a peculiar pyroelectric behavior (a substantial sharp pyroelectric current peak and an unusual continuous pyroelectric current at higher temperatures) which is caused by a combination of Fe spin transition and redistribution of electron density between redox isomers of high-spin Fe through a charge transfer between the Fe atom and redox active ligand. As a result, temperature dependence of the pyroelectric behavior reported here is opposite and originates from the interconversion between three distinct electronic states. The obtained pyroelectric coefficient is comparable to that of polyvinylidene difluoride at room temperature.

Molecular materials based on dynamic electron processes are expected to provide better chemical tailorability, faster switching rates and light switchability ${ }^{1-4}$. The study of molecular compounds with superior physical properties attracts increasing attention because of their fundamental importance and potential applications in pyroelectric sensors ${ }^{5-7}$, digital memory ${ }^{8-11}$ and energy conversion devices ${ }^{12-}$ ${ }^{14}$. One of the key properties is polarization ${ }^{15-17}$. In ferroelectric systems, the collective ion displacement and reorientation of polar molecules are normally utilized to induce changes in polarization ${ }^{18,19}$, and 
so is the intermolecular electron transfer in recent years ${ }^{20-22}$. Indeed, the emergent electron-based polarization properties can be realized by designing compounds whose electronic structure lies at the boundary of multiple states. A number of processes in dynamic molecular crystals, such as spin transition and intramolecular electron transfer, are accompanied by redistribution of electronic density 23. Therefore, such compounds can be potentially used to induce polarization change and hence, the pyroelectric effect ${ }^{24}$. However, research in this regard is still scarce ${ }^{25}$. Pyroelectrics represent a class of non-centrosymmetric polar crystals which consists as inherent coupling between electrical polarization $P$ and temperature $T$, such that a temporal variation in temperature $(\delta T / \delta t)$ results in a change in the electrical dipole moment, that is quantitatively described by the pyroelectric coefficient, $p=(\delta P / \delta T)$. Fundamentally, manifestation of the pyroelectric effect occurs as a temperature-dependent change in the surface-charge density results in a pyroelectric current, $i_{\mathrm{p}}=p A(\delta T / \delta t)$, where $A$ is the area of the measured surface. It should be noted that the conventional pyroelectric effect in ferroelectric systems suffers from a significant temperature-dependent decrease upon cooling from the transition temperature, severely restricting their working temperature ranges ${ }^{26-29}$. On the other hand, those based on discrete molecules can overcome this problem when low-lying electron-transferred states exist, because the gradual population change between such states upon temperature change can induce a continuous current release over a wide temperature range. To develop novel electronic pyroelectric compounds based on such considerations, we designed an $[\mathrm{FeCo}]$ dinuclear complex in which the ligand field strength around the $\mathrm{Fe}^{3+}$ ion is in the spin crossover (SCO) region, and the redox active deprotonated 2,5-dihydroxy-1,4-benzoquinone (dhbq) is used as a bridging ligand. Indeed, an unusual pyroelectric behavior, originating from the electron redistribution between three electronic states, is induced. At approximately $90 \mathrm{~K}$, an abrupt spin transition from highly covalent $\mathrm{Fe}^{3+} \mathrm{LS}^{\text {to }} \mathrm{Fe}^{3+} \mathrm{HS}_{\mathrm{O}}$ ccurs (LS = low spin, HS = high spin) accompanied by partial ligand-to-metal charge redistribution, which is 
followed by a temperature-induced continuous population change between two redox isomers with the structure of $\left[\mathrm{Fe}^{3+} \mathrm{HS}^{-}-\mathrm{dhbq}^{3-}-\mathrm{Co}^{3+} \mathrm{LS}\right]$ and $\left[\mathrm{Fe}^{2+} \mathrm{HS}^{-} \mathrm{dhbq}^{2-}-\mathrm{Co}^{3+} \mathrm{LS}\right]$. Thus, two different types of pyroelectric effects emerge because of the dynamic change in spin and charge in the polar [FeCo] crystal. A pyroelectric current peak is observed at the spin transition temperature because of charge redistribution between $\mathrm{Fe}$ and the dhbq ligand, whereas an approximately constant and relatively large pyroelectric current is observed above the spin transition temperature due to the successive population of the electron-transferred $\left[\mathrm{Fe}^{2+}{ }_{\mathrm{HS}}-\mathrm{dhbq}^{2-}-\mathrm{Co}^{3+} \mathrm{LS}\right]$ state. The crystal of the $[\mathrm{FeCo}]$ complex represents an intricate and ingenious example of electronic pyroelectricity, to which three electronic structures contribute.

\section{Results}

Synthesis and structural characterization. Polar crystals of [FeCo] dinuclear complex were synthesized using the chiral ligands $S S$-cth and $R R$-cth (cth $=5,5,7,12,12,14$-hexamethyl-1,4,8,11tetraazacyclotetradecane) as previously reported ${ }^{30}$. Enantiopure mononuclear complexes of Fe and Co, i.e., $[\mathrm{Fe}(\mathrm{AcO})(R R$-cth $)]\left(\mathrm{PF}_{6}\right)$ and $[\mathrm{Co}(\mathrm{AcO})(S S$-cth $)]\left(\mathrm{PF}_{6}\right)$, were mixed in a methanolic solution of dhbq in an equimolar ratio. The resulting mixture was then oxidized by $\mathrm{AgPF}_{6}$, affording the complex $\left[(\mathrm{Fe}(R R\right.$-cth $))(\mathrm{Co}(S S$-cth $))(\mu$-dhbq) $]\left(\mathrm{PF}_{6}\right)_{3}\left(\mathbf{1}_{\left.\left(\mathbf{P F}_{6}\right)_{3}\right)}\right)$ as dark brown block-shaped crystals. The ESI-MS spectrum of $\mathbf{1}\left(\mathbf{P F}_{\mathbf{6}}\right)_{3}$ in acetone exhibits the molecular peak of the $[\mathrm{FeCo}]$ dinuclear complex $(\mathrm{m} / \mathrm{z}=$ $1111.5)$ with a correct isotopic distribution, together with peaks attributable to [CoCo] and $[\mathrm{FeFe}]$ complexes (Supplementary Fig. 1). An elemental analysis including Co and Fe reveals that the experimental result is in agreement with the calculated one, where $\mathrm{Co} / \mathrm{Fe}$ ratio is 1.00 (Supplementary Table 1). These results suggest that the selective crystallization of an $[\mathrm{FeCo}]$ heterometallic dinuclear complex occurs ${ }^{30}$. A variable-temperature single-crystal analysis reveals that complex $\mathbf{1}\left(\mathbf{P F}_{6} \mathbf{B}_{3}\right.$ crystallizes in the polar $P 2_{1}$ space group (Supplementary Table 2). The corresponding structural data 
show that the discrete cationic molecules of $[1]^{3+}$ comprise $[\Lambda-\mathrm{Fe}(R R$-cth $)]$ and $[\Delta-\mathrm{Co}(S S$-cth $)]$ moieties bridged by a dhbq ligand (Fig. 1a). It is important to note that the Fe-to-Co orientation in each [Fedhbq-Co] unit is almost entirely aligned in the same direction along the b-axis in the structure of $[(R R$ cth $) \mathrm{FeCo}(S S$-cth) $]-[(R R$-cth $) \mathrm{FeCo}(S S$-cth) $]-[(R R$-cth $) \mathrm{FeCo}(S S$-cth $)]$ throughout the crystal, as restricted by the crystalline 2 -screw axis (Fig. 1b). As $\mathrm{SCO}$ in $\mathrm{Fe}^{3+31,32}$ and valence tautomerism in $\mathrm{Co}^{33,34}$ have been frequently observed in metal-catecholate systems, single-crystal structures obtained at various temperatures were compared ${ }^{30,31}$. The bond lengths around the $\mathrm{Fe}$ ions $(\mathrm{Fe}-\mathrm{O}, 1.904(5) \AA ; \mathrm{Fe}-\mathrm{N}$,

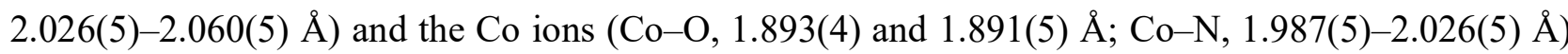
at $60 \mathrm{~K}$ clearly reveal that both ions are in LS state (Supplementary Table 3, Supplementary Figs. 2 and 3). Upon heating to $100 \mathrm{~K}$, the bond lengths around the $\mathrm{Fe}$ ions exhibit a significant elongation ( $\mathrm{Fe}-\mathrm{O}$, 1.987(4) and 1.991(5) $\AA ; \mathrm{Fe}-\mathrm{N}, 2.109(5)-2.145(5) \AA)$, suggesting that the Fe ions are in HS state in this condition. In contrast, the bond lengths around the Co ions remain almost unchanged $(\mathrm{Co}-\mathrm{O}$, 1.893(4) and 1.891(5) $\AA ;$ Co-N, 1.979(5)-2.024(5) $\AA$ ) and typical of the $\mathrm{Co}^{3+} \mathrm{LS}$ state. Moreover, X-ray absorption near edge spectroscopy (XANES) measurements at the Co K-edge further support that Co sites remain unaltered during the transition process. Variable temperature measurements show only very subtle temperature dependence in the Co K-edge spectra, which indicates that the thermally induced spin transition must occur at the Fe site. The Co pre-edge includes one low intensity peak consistent with the $1 \mathrm{~s} \rightarrow 3 \mathrm{~d}$ quadrupole transition for octahedral $\mathrm{Co}^{3+}{ }_{\mathrm{LS}}$. The ${ }^{1} \mathrm{~A}_{1 \mathrm{~g}}$ ground state has one allowed excited configuration, $\mathrm{t}_{2 \mathrm{~g}}{ }^{6} \mathrm{e}_{\mathrm{g}}{ }^{1}$, resulting in a ${ }^{2} \mathrm{E}$ doublet excited absorption state that gives rise to observed single pre-edge feature (Fig. 2 b) ${ }^{35}$

Magnetic Property. The magnetic properties of a polycrystalline sample of complex $\mathbf{1}\left(\mathbf{P F}_{6}\right)_{3}$ were measured under an applied field of $0.1 \mathrm{~T}$ to determine the valence and spin state of the metal centers (Fig. 3) ${ }^{36}$. The $\chi_{\mathrm{m}} T$ product was determined to be $3.12 \mathrm{~cm}^{3} \mathrm{~K} \mathrm{~mol}^{-1}$ at $300 \mathrm{~K}$, which corresponds to a 
system with a total spin quantum number $(S)$ of 2 . A gradual decrease to $3.00 \mathrm{~cm}^{3} \mathrm{~K} \mathrm{~mol}^{-1}$ is then observed upon cooling down to $120 \mathrm{~K}$. On further cooling, the $\chi_{\mathrm{m}} T$ value abruptly decreases at approximately $90 \mathrm{~K}$, reaching to $0.15 \mathrm{~cm}^{3} \mathrm{~K} \mathrm{~mol}^{-1}$ at $5 \mathrm{~K}$, indicating that the majority of the molecules populate a diamagnetic state $(S=0)$. The ligand field around the Fe center is known to be appropriate for the spin crossover in $\mathrm{Fe}^{3+}$ ion, therefore, the observed behavior can be inferred as the occurrence of the spin transition between the strongly antiferromagnetically (AF) coupled $\mathrm{Fe}^{3+} \mathrm{LS}^{-} \mathrm{dhbq}^{3-}$ and $\mathrm{Fe}^{3+}{ }_{\mathrm{HS}}-\mathrm{dhbq}^{3-}$ states. The strong AF interaction could be the result from strong covalency between the $\mathrm{Fe}^{3+}$ ion and the radical bearing ligand, which introduces a contribution from the charge-transferred component $\left(\mathrm{Fe}^{2+} \mathrm{LS}^{-} \mathrm{dhbq}^{2-}\right)$ to the ground electronic configuration in $\mathbf{1}\left(\mathbf{P F}_{\mathbf{6}}\right)_{3}{ }^{37}$.

Pyroelectric property. The complex $\mathbf{1}\left(\mathbf{P F}_{6}\right)_{3}$ crystallizes in the polar space group, enabling the observation of the pyroelectric effect from the peculiar change in the electronic structure upon varying the temperature. To unambiguously determine the direction of the pyroelectric current with respect to the single crystal, a plate-like piece of complex $\mathbf{1}\left(\mathbf{P F}_{\mathbf{6}}\right)_{3}$ crystal was indexed with silver paste attached to one side of the crystal surface and carbon paste attached to the parallel surface and the faces $(010)$ and $(0-10)$ were distinguished. The sign of the pyroelectric coefficient formally corresponds to the electron transfer from dhbq to $\mathrm{Fe}$ in the whole temperature range upon heating. Below $60 \mathrm{~K}$, only a weak current signal is detected upon heating, corresponding to a pyroelectric coefficient of less than $0.3 \mathrm{nC} \mathrm{cm}^{-2} \mathrm{~K}^{-1}$ (Fig. 4a). At a temperature approaching the abrupt transition point, the pyroelectric current exhibits a sharp increase, giving a peak as high as $30 \mathrm{nC} \mathrm{cm}^{-2} \mathrm{~K}^{-1}$, and then decreases to ca. 3.8 $\mathrm{nC} \mathrm{cm}{ }^{-2} \mathrm{~K}^{-1}$ after $120 \mathrm{~K}$. This is clearly associated with the redistribution of electronic density in the $[\mathrm{FeCo}]$ complex in a narrow temperature range during the spin transition process. Integration over this temperature domain gives a polarization change of approximately $0.4 \mu \mathrm{C} \mathrm{cm}^{-2}$ (Fig. $4 \mathrm{~b}$ ). Upon further heating to room temperature, it is surprising to find that the pyroelectric current is still detected, and the 
pyroelectric coefficient remains at approximately $3.4 \mathrm{nC} \mathrm{cm}^{-2} \mathrm{~K}^{-1}$ at $300 \mathrm{~K}$, which is as large as that of polyvinylidene difluoride (PVDF) ${ }^{38}$. However, the pyroelectric property is known to be inherent to materials with polar structures. In the case of $\mathbf{1}\left(\mathbf{P F}_{\mathbf{6}}\right)_{\mathbf{3}}$, the pyroelectric behavior could stem not only from the possible intramolecular electron transfer but also from a change in the strain of the crystal sample. To discriminate between these two contributions and to exclude the possibility that the pyroelectric current above the spin transition originates from a secondary pyroelectric effect due to the thermal deformation of the polar crystal, we measured the pyroelectric property of an isostructural [ZnCo] dinuclear complex (Supplementary Figs. 4 and Supplementary Table 5) as a reference material without charge transfer behavior. The pyroelectric coefficient of the $[\mathrm{ZnCo}]$ complex was found to be much smaller $(<15 \%)$ than that observed for $\mathbf{1}\left(\mathbf{P F}_{6}\right)_{3}$ in the whole temperature range, supporting that the large pyroelectric coefficient of $\mathbf{1}\left(\mathbf{P F}_{6}\right)_{3}$ mainly originates from a continuous electronic redistribution in the compound.

\section{Discussion}

Further in-depth spectroscopic and theoretical investigation was carried out in pursuit of the origin of the exotic and unusual pyroelectric behavior in terms of the electronic structure determination at different temperature regime.

The electronic structures of this system in the LT phase were examined through a combination of theoretical and variable-temperature spectroscopic studies ${ }^{30}$. Infrared (IR) spectra recorded below 70 K exhibit no significant change in the peak positions and intensities. The strong absorption band at 1485 $\mathrm{cm}^{-1}$ is typical of the open-shell $\mathrm{dhbq}^{3-}$ bridging ligand, as observed in similar $\left[\mathrm{Co}^{3+} \mathrm{LS}^{-} \mathrm{dhbq}^{3-}-\mathrm{Co}^{3+} \mathrm{LS}^{-}\right]$ and $\left[\mathrm{Cr}^{3+}-\mathrm{dhbq}^{3-}-\mathrm{Co}^{3+} \mathrm{LS}\right]$ compounds (Supplementary Fig. 5) ${ }^{30,33}$. Indeed, density functional theory (DFT) calculations confirm the assignment of $\mathrm{dhbq}^{3-}$ state of the bridging ligand; the antiferromagnetically coupled $\left[\mathrm{Fe}^{3+}{ }_{\mathrm{LS}}-\mathrm{dhbq}^{3-}-\mathrm{Co}^{3+} \mathrm{LS}\right]$ state is energetically slightly lower than the 
electron-transferred $\left[\mathrm{Fe}^{2+}{ }_{\mathrm{LS}}-\mathrm{dhbq}^{2-}-\mathrm{Co}^{3+} \mathrm{LS}\right]$ state by $1.91 \mathrm{kcal} \mathrm{mol}^{-1}$. A vibrational analysis based on the $\mathrm{AF}\left[\mathrm{Fe}^{3+} \mathrm{LS}_{-}-\mathrm{dhbq}^{3-}-\mathrm{Co}^{3+} \mathrm{LS}\right]$ state also provides a reasonable match with the experimental IR spectra in the 1200 to $1600 \mathrm{~cm}^{-1}$ region measured below $80 \mathrm{~K}$, supporting our assignment of the LT electronic structure of $\left[\mathrm{Fe}^{3+} \mathrm{LS}_{-} \mathrm{dhbq}^{3-}-\mathrm{Co}^{3+} \mathrm{LS}\right]$ state (Supplementary Figs. 6 and 7). To gain more information about the electronic structure of the Fe ion, its Mössbauer spectrum is recorded at $75 \mathrm{~K}$. The isomer shift (IS) and quadrupole splitting (QS) of 0.42 and $1.64 \mathrm{~mm} \mathrm{~s}^{-1}$, respectively, were obtained (Supplementary Fig. 9 and Supplementary Table 4). Notably, the QS value is well comparable to those observed in the LS state of catecholato- $\mathrm{Fe}^{3+} \mathrm{SCO}$ compounds decorated by electron-donating groups, smaller than the typical values $\left(>2.0 \mathrm{~mm} \mathrm{~s}^{-1}\right)$ for the ferric compounds in similar coordination environment ${ }^{31,39}$. This has been considered as the signature of the presence of quantum mixing of $\mathrm{Fe}^{2+}$ LS component. Fe K-edge XANES measurements performed at $8 \mathrm{~K}$ resolve a single low-intensity (5.1 units of intensity) pre-edge peak, which is typical for octahedral $\mathrm{Fe}^{2+} \mathrm{LS}$ rather than $\mathrm{Fe}^{3+} \mathrm{LS}$ (Fig. $5 a)^{40}$. To investigate the pre-edge in greater detail high energy resolution fluorescence detected (HERFD) XANES measurements were performed. The HERFD spectrum resolves additional fine structure within the pre-edge region (Fig. 5b). Interpretation of these features matches neither $\mathrm{Fe}^{2+} \mathrm{LS}$ or $\mathrm{Fe}^{3+}$ LS limiting descriptions. In the $\mathrm{Fe}^{3+}$ LS limiting description the HERFD spectrum includes a characteristic low-energy ${ }^{1} \mathrm{~A}_{\mathrm{lg}}\left(\mathrm{t}_{2 \mathrm{~g}}{ }^{6} \mathrm{eg}_{\mathrm{g}}{ }^{\mathrm{a}}\right.$ ) absorption final state followed by a series of overlapping absorption final states $\left({ }^{3} \mathrm{~T}_{1 \mathrm{~g}},{ }^{3} \mathrm{~T}_{2 \mathrm{~g}},{ }^{1} \mathrm{~T}_{1 \mathrm{~g}}\right.$ and $\left.{ }^{1} \mathrm{~T}_{2 \mathrm{~g}}\right)$ at higher energy that originate from multiplet splitting within the $\mathrm{t}_{2 \mathrm{~g}}{ }^{5} \mathrm{e}_{\mathrm{g}}{ }^{1}$ absorption configuration. In the $\mathrm{Fe}^{2+} \mathrm{LS}$ limiting description the HERFD spectrum is dominated by just one absorption peak, relating to ${ }^{2} E_{g}\left(t_{2 g}{ }^{6} e_{g}{ }^{1}\right)$ absorption final state. ${ }^{40,41}$ Fitting the individual contributions to the $8 \mathrm{~K}$ HERFD spectrum of $\mathbf{1}\left(\mathbf{P F}_{\mathbf{6}}\right)_{3}$ requires a minimum of three peaks (Fig. 5b), supporting Mössbauer evidence that the ground state is composed of a strongly mixing combination of both $\mathrm{Fe}^{2+} \mathrm{LS}$ and $\mathrm{Fe}^{3+}$ LS. These observations point toward the highly covalent $\left[\mathrm{Fe}^{3+}{ }_{\mathrm{LS}}^{-}\right.$ 
$\left.\mathrm{dhbq}^{3-}-\mathrm{Co}^{3+} \mathrm{LS}\right]$ state, with significant contribution from $\left[\mathrm{Fe}^{2+} \mathrm{LS}^{-} \mathrm{dhbq}^{2-}-\mathrm{Co}^{3+} \mathrm{LS}\right]$ state as the ground configuration below the transition temperature. This analysis is consistent with the above-mentioned DFT calculations; the reduction of spin density on Fe ion (0.73) reflects the high covalency between Fe and dhbq ligand. Considering the small energy difference between $\left[\mathrm{Fe}^{3+} \mathrm{LS}^{-} \mathrm{dhbq}^{3-}-\mathrm{Co}^{3+} \mathrm{LS}\right]$ and $\left[\mathrm{Fe}^{2+} \mathrm{LS}^{-}\right.$ $\left.\mathrm{dhbq}^{2-}-\mathrm{Co}^{3+} \mathrm{LS}\right]$ states and their nearness on the potential energy surface, a multi-configuration description would be more appropriate.

To understand the nature of the observed transition behavior and gain insight into the electronic structure at the HT phase, the Fe XANES measurements were performed at $250 \mathrm{~K}$. The energy of the absorption edge threshold is consistent with $\mathrm{Fe}^{3+}{ }_{\mathrm{HS}}$ ion (Fig. 2a). However, the relative intensities of the pre-edge peaks are inconsistent with quadrupole allowed transitions expected for octahedral $\mathrm{Fe}^{3+} \mathrm{HS}$ ion (Fig. 5c). The lower energy peak is much less intense than the higher energy peak, which is inconsistent with the 3:2 peak ratio expected for $\mathrm{Fe}^{3+} \mathrm{HS}$ with a ${ }^{5} \mathrm{~A}_{1 \mathrm{~g}}\left(\mathrm{t}_{2 \mathrm{~g}}{ }^{3} \mathrm{eg}_{\mathrm{g}}{ }^{2}\right)$ ground state and ${ }^{5} \mathrm{~T}_{2}\left(\mathrm{t}_{2 \mathrm{~g}}{ }^{4}\right.$ $\left.\mathrm{eg}_{\mathrm{g}}{ }^{2}\right)$ and ${ }^{5} \mathrm{E}\left(\mathrm{t}_{2 \mathrm{~g}}{ }^{3} \mathrm{eg}_{\mathrm{g}}{ }^{3}\right)$ final states. The pre-edge has 8.8 units of intensity, which fits within the range expected for distorted six coordinate $\mathrm{Fe}^{2+}{ }_{\mathrm{HS}}{ }^{42}$ To analyze the pre-edge in greater detail, HERFDXANES were performed, and show that the pre-edge structure is neither consistent with octahedral $\mathrm{Fe}^{3+}{ }_{\mathrm{HS}}$ or $\mathrm{Fe}^{2+} \mathrm{HS}$, providing further evidence of either quantum mixing of $\mathrm{Fe}^{2+} \mathrm{HS}$ wavefunction in the ground state, or the population of $\left[\mathrm{Fe}^{2+} \mathrm{HS}_{-} \mathrm{dhbq}^{2-}-\mathrm{Co}^{3+} \mathrm{LS}\right]$ state (Fig. 5d). The HERFD-XANES measurements performed at $250 \mathrm{~K}$ provides almost identical pre-edge structure to those obtained at 135 $\mathrm{K}$, and the origin of the high-temperature pyroelectricity remained unsettled (Supplementary Fig. 8).

The Mössbauer spectrum recorded above the transition temperature $(125 \mathrm{~K})$ affords IS and QS values of 0.69 and $1.83 \mathrm{~mm} \mathrm{~s}^{-1}$, respectively (Fig. 7, Supplementary Fig. 9 and Supplementary Table 4). The QS value is considerably larger than that $\left(\sim 1.0 \mathrm{~mm} \mathrm{~s}^{-1}\right)$ of the $\mathrm{Fe}^{3+} \mathrm{HS}$ state in reference $\left[\mathrm{Fe}(\mathrm{cth})_{2}(\mathrm{dhbq})\right]^{3+}$ compound ${ }^{43}$. Normally, the QS value decreases with pure spin transition from $\mathrm{Fe}^{3+} \mathrm{LS}$ 
to $\mathrm{Fe}^{3+}{ }_{\text {HS state; }}$ the observed increase in the QS value of $\mathbf{1}\left(\mathbf{P F}_{6}\right)_{3}$ after the transition upon heating thus indicates that the electronic state just above the transition temperature is not purely determined by the $\mathrm{Fe}^{3+} \mathrm{HS}_{\text {state. The }} \mathrm{Fe}^{2+}{ }_{\mathrm{HS}}$ state having a larger QS value (typically, 2.1-2.9 $\mathrm{mm} \mathrm{s}^{-1}$ ) ${ }^{43}$ should also contribute to the electronic structure, which is consistent with the results from XANES measurements at the Fe K-edge. Notably, no distinct peaks are resolved by Mössbauer spectroscopy, which suggests that the rates of electron hopping occurring between $\mathrm{Fe}$ and the dhbq ligand are faster than the Mössbauer time window $\left(\tau \sim 10^{-8} \mathrm{~s}\right)$.

IR measurements evidence a change in the spectra at the transition temperature range (80-100 K), which consists of an abrupt decrease of the absorption bands around $1329 \mathrm{~cm}^{-1}$ and the appearance of new bands at 1514 and $1296 \mathrm{~cm}^{-1}$ (Fig. 6). This means that the change in the spin state of the Fe ion is accompanied by variations in the electronic structure of the bridging ligand. Upon increasing temperature, it was found that the peaks around $1485 \mathrm{~cm}^{-1}$, characteristic of $\mathrm{dhbq}^{3-}$, continuously decrease in intensity, whereas a new peak around $1556 \mathrm{~cm}^{-1}$, characteristic of $\mathrm{dhbq}^{2-}$, emerges and increases upon heating (Supplementary Figs. 5 and 10) as typically observed in reported valence tautomeric dinuclear compounds ${ }^{30,44}$. Such features reveal that the $\left[\mathrm{Fe}^{2+} \mathrm{HS}^{-} \mathrm{dhbq}^{2-}-\mathrm{Co}^{3+} \mathrm{LS}\right]$ state gradually becomes the dominating phase in thermal equilibrium with the $\left[\mathrm{Fe}^{3+} \mathrm{HS}^{-} \mathrm{dhbq}^{3-}-\mathrm{Co}^{3+} \mathrm{LS}^{-} \mathrm{state}\right.$ at the HT phase (Fig. 6). This scenario is supported by theoretical calculations (Supplementary Fig. 7). Mössbauer measurements up to higher temperatures also show a gradual increase in the QS and IS values upon heating, providing further evidence of the increasing population on the $\mathrm{Fe}^{2+} \mathrm{HS}$ state with larger QS values at higher temperatures (Fig. 7). However, no well-resolved peaks can be observed during this process, suggesting that the rates of electron hopping process are faster than the Mössbauer time window $\left(\tau \sim 10^{-8} \mathrm{~s}\right)$ but slower than the IR time window $\left(\tau \sim 10^{-12} \mathrm{~s}\right)$. SC-XRD also provides evidence for the electronic dynamics in $\mathbf{1}\left(\mathbf{P F}_{6}\right)_{3}$. As summarized in Supplementary Figs. 2 and 3, upon 
further heating above $100 \mathrm{~K}$, the $\mathrm{Fe}-\mathrm{O}$ bond lengths undergo a continuous elongation, whereas the $\mathrm{Co}-$ O bond lengths near the Fe site show a temperature-dependent decrease, which may be attributed to the occurrence of additional electron dynamics after the abrupt magnetic transition process. Notably, such changes in the bond lengths resemble those observed in the valence tautomeric Fe-semiquinonato chain systems ${ }^{36,37}$.

The experimental and calculation results reveal that the interconversion between mixed-valance electronic states is the origin of the pyroelectric effect, at a difference with typical ferroelectric compounds. Furthermore, the pyroelectric current is normally observed below the ferroelectric transition temperature in ferroelectrics. On the other hand, for the polar [FeCo] complex, the current is observed at the HT phase. Importantly, because of the gradual population change between $\left[\mathrm{Fe}^{2+} \mathrm{HS}^{-}\right.$ $\left.\mathrm{dhbq}^{2-}-\mathrm{Co}^{3+}{ }_{\mathrm{LS}}\right]$ and $\left[\mathrm{Fe}^{3+} \mathrm{HS}^{-} \mathrm{dhbq}^{3-}-\mathrm{Co}^{3+} \mathrm{LS}\right]$ states, an almost continuous pyroelectric current comparable to that of PVDF is observed in a wide temperature range from $90 \mathrm{~K}$ up to room temperature, which has never been reported and is essential for application development. Note that these pyroelectric properties can be repeatedly observed in the absence of an electric field because the molecular orientation is fixed in the $\mathbf{1}\left(\mathbf{P F}_{6}\right)_{\mathbf{3}}$ crystal. This contrasts with the properties of ferroelectric compounds, for which application of an electric field to align the polar direction is required beforehand.

\section{Conclusion}

This study presented electronic pyroelectric crystals of the $[\mathrm{FeCo}]$ dinuclear complex $[(\mathrm{Fe}(R R-$ cth $)\left(\mathrm{Co}(S S\right.$-cth $)(\mu$-dhbq) $]\left(\mathrm{PF}_{6}\right)_{3}$. The $[\mathrm{FeCo}]$ complex has three thermally accessible states, whose interconversion is induced upon changing the temperature. The ground state exhibits a highly covalent $\left[\mathrm{Fe}^{3+} \mathrm{LS}^{-} \mathrm{dhbq}^{3-}-\mathrm{Co}^{3+} \mathrm{LS}\right]$ state with considerable contribution from the $\left[\mathrm{Fe}^{2+} \mathrm{LS}^{-}-\mathrm{dhbq}^{2-}-\mathrm{Co}^{3+} \mathrm{LS}\right]$ state at very low temperatures. At approximately $90 \mathrm{~K}$, it transforms into an equilibrium between $\left[\mathrm{Fe}^{3+} \mathrm{HS}^{-}\right.$ $\left.\mathrm{dhbq}^{3-}-\mathrm{Co}^{3+} \mathrm{LS}\right]$ and $\left[\mathrm{Fe}^{2+} \mathrm{HS}^{-} \mathrm{dhbq}^{2-}-\mathrm{Co}^{3+}{ }_{\mathrm{LS}}\right]$ states, in which the $\left[\mathrm{Fe}^{3+} \mathrm{HS}^{-}-\mathrm{dhbq}^{3-}-\mathrm{Co}^{3+} \mathrm{LS}^{3}\right]$ state 
dominates just above the spin transition temperature, and the population of the $\left[\mathrm{Fe}^{2+} \mathrm{HS}^{-} \mathrm{dhbq}^{2-}-\mathrm{Co}^{3+} \mathrm{Ls}\right]$ state increases with temperature. Since the $[\mathrm{FeCo}]$ dinuclear complexes are designed to orient in the same direction within the crystal, the unusual transition between the three states can be envisaged as the origin of the pyroelectric effect. Our work demonstrates the possibility that large pyroelectric effect can be preserved up to high temperatures with a continuous current release. Note that while energy conversion from waste heat to electric power can be realized in high-temperature ferroelectrics, we show that dynamic molecular materials by sophisticated chemical design can be exploited for the same purpose without a ferroelectric transition.

\section{Methods}

All solvents and reagents were used as received. Racemic-cth and the enantiopure ligands $(R R$-cth and $S S$-cth) (cth $=5,5,7,12,12,14$-hexamethyl-1,4,8,11-tetraazacyclotetradecane) were prepared according to literature proceedures ${ }^{45}$. All reactions were conducted under a dry $\mathrm{N}_{2}$ atmosphere.

Synthesis of enantiopure $[\mathbf{F e}(\mathbf{A c O})(\boldsymbol{R} \boldsymbol{R}-\mathrm{cth})]\left(\mathbf{P F}_{6}\right)$ : A mixture of $\mathrm{Fe}(\mathrm{AcO})_{2}(521 \mathrm{mg}, 3.0 \mathrm{mmol})$ and $R R$-cth $(850 \mathrm{mg}, 3.0 \mathrm{mmol})$ in $\mathrm{EtOH}(10 \mathrm{ml})$ was heated to $60^{\circ} \mathrm{C}$ under a $\mathrm{N}_{2}$ atmosphere. After stirring at this temperature, solid $\mathrm{NH}_{4} \mathrm{PF}_{6}(540 \mathrm{mg}, 3.3 \mathrm{mmol})$ was added to the solution. $[\mathrm{Fe}(\mathrm{AcO})(R R$ cth) $]\left(\mathrm{PF}_{6}\right)$ then gradually precipitated within an hour. After the reaction mixture was cooled in an icebath, a precipitate was collected by filtration and washed with cold $\mathrm{EtOH}$ followed by $\mathrm{Et}_{2} \mathrm{O}$. $[\mathrm{Fe}(\mathrm{AcO})(R R$-cth $)]\left(\mathrm{PF}_{6}\right)$ was obtained as an off-white crystalline solid $(1.286 \mathrm{~g}$, yield $=78 \%)$. Anal. $\mathrm{C}_{18} \mathrm{H}_{39} \mathrm{~N}_{4} \mathrm{O}_{2} \mathrm{~F}_{6} \mathrm{PFe}(544.34)$ Calcd. C: 39.72, H: 7.22, N: 10.29; found C: 39.69, H: 7.21, N: 10.31 . Synthesis of enantiopure [Co(AcO)(SS-cth)](PF $)$ : A mixture of $\mathrm{Co}(\mathrm{AcO})_{2} \cdot 4 \mathrm{H}_{2} \mathrm{O}(747 \mathrm{mg}, 3.0$ $\mathrm{mmol})$ and $S S$-cth $(850 \mathrm{mg}, 3.0 \mathrm{mmol})$ in $\mathrm{EtOH}(10 \mathrm{ml})$ was heated to $60^{\circ} \mathrm{C}$ under a $\mathrm{N}_{2}$ atmosphere. After stirring at this temperature, solid $\mathrm{NH}_{4} \mathrm{PF}_{6}(540 \mathrm{mg}, 3.3 \mathrm{mmol})$ was added to the solution. 
$[\mathrm{Co}(\mathrm{AcO})(S S$-cth $)]\left(\mathrm{PF}_{6}\right)$ then gradually precipitated within an hour. After the reaction mixture was cooled in an ice-bath, a precipitate was collected by filtration and washed with cold EtOH followed by $\mathrm{Et}_{2} \mathrm{O} .[\mathrm{Co}(\mathrm{AcO})(\mathrm{SS}$-cth $)]\left(\mathrm{PF}_{6}\right)$ was obtained as light pink crystalline solid $(1.23 \mathrm{~g}$, yield $=75 \%)$. Anal. $\mathrm{C}_{18} \mathrm{H}_{39} \mathrm{~N}_{4} \mathrm{O}_{2} \mathrm{~F}_{6} \mathrm{PCo}(547.42)$ Calcd. C: 39.49, H: 7.18, N: 10.23; found C: 39.46, H: 7.19, N: 10.27. Synthesis of $\left[(\mathrm{Fe}(R R\right.$-cth $))(\mathrm{Co}(S S$-cth $))(\mu$-dhbq) $]\left(\mathrm{PF}_{6}\right) 2:$ A solution of 3,5 -dihydroxy-1,4benzoquinone $\left(\mathrm{H}_{2} \mathrm{dhbq} ; 140 \mathrm{mg}, 1.0 \mathrm{mmol}\right)$ and triethylamine $(0.3 \mathrm{ml}, 2.0 \mathrm{mmol})$ in $\mathrm{MeOH}(50 \mathrm{ml})$ was bubbled with dry $\mathrm{N}_{2}$ gas for 10 min to remove oxygen. Subsequently, solid $[\mathrm{Fe}(\mathrm{AcO})(R R$-cth $)]\left(\mathrm{PF}_{6}\right)$ (544 mg, $1.0 \mathrm{mmol})$ and $[\mathrm{Co}(\mathrm{AcO})(S S$-cth $)]\left(\mathrm{PF}_{6}\right)(547 \mathrm{mg}, 1.0 \mathrm{mmol})$ were added to the solution, and the reaction mixture was heated at $60^{\circ} \mathrm{C}$ for $30 \mathrm{~min}$. A hot solution of $\mathrm{KPF}_{6}(276 \mathrm{mg}, 1.5 \mathrm{mmol})$ in $\mathrm{H}_{2} \mathrm{O}$ (30 ml) was added to this dark-red solution. The mixture was slowly cooled and then kept at room temperature. After two days, a brown precipitate of $[(\mathrm{Fe}(R R$-cth $))(\mathrm{Co}(S S$-cth $))(\mu$-dhbq $)]\left(\mathrm{PF}_{6}\right)_{2}$ was collected by filtration and washed with $\mathrm{H}_{2} \mathrm{O}$ and cold $\mathrm{MeOH}(630 \mathrm{mg}$, yield $=56 \%)$.

Synthesis of $[(\mathbf{F e}(R R-$-cth $))(\mathbf{C o}(S S$-cth $))(\mu$-dhbq)](PF6)3, 1(PF6)3: Solid AgPF 6 (76 mg, 0.3 mmol) and $\mathrm{H}_{2} \mathrm{O}(1 \mathrm{ml})$ were added to a solution of $\left[(\mathrm{Fe}(R R\right.$-cth $))(\mathrm{Co}(S S$-cth $))(\mu$-dhbq) $]\left(\mathrm{PF}_{6}\right)_{2}(335 \mathrm{mg}, 0.3$ mmol) dissolved in acetone $(60 \mathrm{ml})$. After stirring for $10 \mathrm{~min}$, the mixture was filtered to remove Ag. The filtrate was evaporated to dryness under reduced pressure, and crude $\mathbf{1}\left(\mathbf{P F}_{\mathbf{6}}\right)_{\mathbf{3}}$ was collected as a brown solid and washed with a small amount of $\mathrm{H}_{2} \mathrm{O}$. The crude product was recrystallized from a mixed solvent of several drops of $\mathrm{MeCN}$ and hot $\mathrm{H}_{2} \mathrm{O} / \mathrm{MeOH}$ to afford dark-red crystals suitable for structural analysis $(274 \mathrm{mg}$, yield $=72.9 \%)$. Elemental analysis calcd. for $\mathrm{C}_{38} \mathrm{H}_{74} \mathrm{~N}_{8} \mathrm{O}_{4} \mathrm{~F}_{18} \mathrm{P}_{3} \mathrm{FeCo}$ : C: 36.2, H: 5.8, N: 8.65, Fe: 4.44, Co: 4.69; found: C: 36.41, H: 5.94, N: 8.92, Fe: 4.48, Co: 4.72; ESI MS (Supplementary Fig. 1): $m / z=1111.5\left[1\left(\mathrm{PF}_{6}\right)_{2}\right]^{+}$(calcd for $\mathrm{C}_{38} \mathrm{H}_{74} \mathrm{~N}_{8} \mathrm{O}_{4} \mathrm{~F}_{12} \mathrm{P}_{2} \mathrm{FeCo}$ : 1111.75).

\section{X-ray Spectroscopy}


X-ray spectroscopy measurements were performed at the Stanford Synchrotron Radiation Lightsource (SSRL), operated at $3 \mathrm{GeV}$ with an electron beam current of $500 \mathrm{~mA}$. The measured samples were maintained between $10 \mathrm{~K}$ and $270 \mathrm{~K}$ using an Oxford Instruments CF1208 continuous flow liquid helium cryostat. Orientation averaged powder samples were mixed in boron nitride to alleviate selfabsorption effects. Monochromator energy calibration was performed using the first inflection point of an Fe foil set to $7111.2 \mathrm{eV}$ and Co foil set to $7713.0 \mathrm{eV}$.

Fe K-edge X-ray absorption near edge structure (XANES) measurements were performed at beamline 9-3. The measurements were performed in transmission mode with $\mathrm{N}_{2}$-filled ionization chambers and fluoresce measurements were collected at $90^{\circ}$ to the incident beam using a total fluoresce diode with Soller slits and a Mn filter between the sample and the Soller slits. During measurement, the data in the Fe and Co K-edge and $\mathrm{K}$ pre-edge regions were continuously monitored in order to ensure sample integrity by comparing each individual scan to ones taken previously and minimal photodamage was observed. To minimize contributions from photodamaged product, different spots along the samples were scanned. The spin transition observed in variable temperature Fe K-edge XANES was confirmed to be reversible through a complete heating cooling cycle. Fe high energy resolution fluorescence detected (HERFD) X-ray spectroscopy measurements were performed at the undulator beamline 15-2. A double-crystal monochromator equipped with $\mathrm{Si}(311)$ crystals was used to select the energy with a resolution $(\Delta \mathrm{E} / \mathrm{E})$ of $\sim 10^{-5}$ and two Rh-coated Kirkpatrick-Baez mirrors set a $3.5 \mathrm{mrad}$ delivered a 45 $\mu \mathrm{m}(\mathrm{v}) \times 800-\mu \mathrm{m}(\mathrm{h}) \mathrm{X}$-ray beam to the sample position. The (440) Bragg reflection of five Ge(110) crystals arranged in a $1 \mathrm{~m}$ Rowland geometry were used to select the emission energy with a single element silicon drift detector used to measure the X-ray emission. ${ }^{46}$ The emitted beam path was enclosed by a He-filled bag to reduce the signal attenuation. A liquid He cooled cryostat for measurements at different temperatures was used. To avoid radiation damage, a sample stage that is 
equipped with motors to allow for horizontal and vertical movement for multiple sampling positions was employed. Radiation damage was carefully monitored through consecutive scans at the same spot and the exposure time/dose per irradiated spot was kept well below the levels required for noticeable beam-induced spectral alterations. For each HERFD spectrum the emission detector energy was set to the maximum of the $\mathrm{Fe} \mathrm{K} \alpha 1$ emission line, $6404.52 \mathrm{eV}$ for $\mathrm{Fe}_{\mathrm{LS}}$ and $6404.8 \mathrm{eV}$ for $\mathrm{Fe}_{\mathrm{HS}}$.

Pre-edge peak fitting for both the XANES and HERFD results were performed using a Pearson VII line shapes with a fixed 50:50 ratio of Lorentzian to Gaussian functions where the energy positions, the full width half maximum and the peak heights were varied using a non-linear least squares fitting routine. The normalised XANES pre-edge intensity is defined as the total pre-edge peak area determined by trapezoidal numerical integration of the fitted peaks, multiplied by 100 , where the post-edge of the XANES is normalised to unity.

\section{Pyroelectric measurements}

Pyroelectric measurements were performed with Keithley 6517B electrometer and a Quantum Design MPMS-XL chamber to control the temperature ${ }^{47}$. The single-crystal sample (surface area of 0.3036 $\left.\mathrm{mm}^{2}\right)$ was sandwiched by silver and carbon paste on its (010) and (0-10) surfaces to determine the direction of the pyroelectric current. Data were also recorded on a crystal piece sandwiched by silver paste on both of its sides (Fig. 4) and the results are consistent. No electric field was applied to the sample. The measurement temperature was restricted between 10 and $300 \mathrm{~K}$ under a helium gas flow. The measurements were conducted at a temperature sweep rate of $5 \mathrm{~K} \cdot \mathrm{min}^{-1}$.

\section{Data Availability}

The supplementary crystal data can be obtained free of charge from the Cambridge Crystallographic Data Centre (www.ccdc.cam.ac.uk/data_request/cif) using identifiers CCDC 2025869-2025876. The authors declare that data supporting the findings of this study are available within the paper and its 
supplementary information files. Further data are available from the corresponding authors upon reasonable request.

\section{Acknowledgments}

This work was supported by MEXT KAKENHI Grant Numbers JP20H00385 and JP18K05057. Use of the Stanford Synchrotron Radiation Lightsource, SLAC National Accelerator Laboratory, is supported by the U.S. Department of Energy, Office of Science, Office of Basic Energy Sciences under Contract No. DE-AC02-76SF00515.

\section{Author contributions}

O.S. and S.K. supervised the project. P.S., J.I.L. and T.N. carried out synthetic and crystallographic experiments. Pyroelectric measurement was performed by K.G., J.I.L., S.K. and K.Y. M.L.B. measured the XANES spectra. M.L.B., T.K. and D.S. measured and analysed the HERFD spectra. A.O. and N.K. undertook the spectra of Mössbauer. H.O. and A.S. performed the IR measurements. S.-Q.W., Y.S. and K.Y. have carried out theoretical analysis. S.-Q.W., P.S., S.K. and O.S. discussed and co-wrote the manuscript.

\section{Competing interests}

The authors declare no competing financial interests.

\section{Additional information}

Supplementary Information is available in the online version of the paper.

Corresponding author: Correspondence and requests for materials should be addressed to S. K. (email: kanegawa@cm.kyushu-u.ac.jp) or to O.S. (email: sato@cm.kyushu-u.ac.jp). 


\section{References}

1 Sato, O. Dynamic molecular crystals with switchable physical properties. Nature Chemistry 8, 644-656 (2016).

2 Yam, V. W.-W., Chan, A. K.-W. \& Hong, E. Y.-H. Charge-transfer processes in metal complexes enable luminescence and memory functions. Nature Reviews Chemistry (2020).

3 Wang, Z. et al. Light-induced pyroelectric effect as an effective approach for ultrafast ultraviolet nanosensing. Nature Communications 6, 8401 (2015).

4 Tezgerevska, T., Alley, K. G. \& Boskovic, C. Valence tautomerism in metal complexes: Stimulated and reversible intramolecular electron transfer between metal centers and organic ligands. Coordination Chemistry Reviews 268, 23-40 (2014).

5 Lang, S. B. \& Muensit, S. Review of some lesser-known applications of piezoelectric and pyroelectric polymers. Applied Physics A 85, 125-134 (2006).

6 Hossain, A. \& Rashid, M. H. Pyroelectric detectors and their applications. IEEE Transactions on Industry Applications 27, 824-829 (1991).

7 He, H. et al. Advances in lead-free pyroelectric materials: a comprehensive review. Journal of Materials Chemistry C 8, 1494-1516 (2020).

8 Gatteschi, D. Molecular Magnetism: A basis for new materials. Advanced Materials 6, 635-645 (1994).

9 Sato, O., Tao, J. \& Zhang, Y.-Z. Control of Magnetic Properties through External Stimuli. Angewandte Chemie International Edition 46, 2152-2187 (2007).

10 Guo, F.-S. et al. Magnetic hysteresis up to 80 kelvin in a dysprosium metallocene singlemolecule magnet. Science 362, 1400-1403 (2018).

11 Coronado, E. Molecular magnetism: from chemical design to spin control in molecules, materials and devices. Nature Reviews Materials 5, 87-104 (2020).

12 Pandya, S. et al. New approach to waste-heat energy harvesting: pyroelectric energy conversion. NPG Asia Materials 11, 26 (2019).

13 Bowen, C. R. et al. Pyroelectric materials and devices for energy harvesting applications. Energy \& Environmental Science 7, 3836-3856 (2014).

14 Huang, H. \& Scott, J. F. Ferroelectric Materials for Energy Applications (Wiley-VCH, Germany, 2018). 
15 Lines, M. E. G. \& Glass, A. M. Principles and Applications of Ferroelectrics and Related Materials (Oxford Univ. Press, New York, 1977).

16 Sworakowski, J. Ferroelectricity and related properties of molecular solids. Ferroelectrics 128, 295-306 (1992).

17 Ishihara, S. Electronic ferroelectricity in molecular organic crystals. Journal of Physics: Condensed Matter 26, 493201 (2014).

18 Katrusiak, A. \& Szafrański, M. Ferroelectricity in $\mathrm{NH}^{\cdots}$ N Hydrogen Bonded Crystals. Physical Review Letters 82, 576-579 (1999).

19 Miyajima, D. et al. Ferroelectric columnar liquid crystal featuring confined polar groups within core-shell architecture. Science 336, 209-213 (2012).

20 Yamamoto, K. et al. Strong Optical Nonlinearity and its Ultrafast Response Associated with Electron Ferroelectricity in an Organic Conductor. Journal of the Physical Society of Japan 77, 074709 (2008).

21 Takehara, R. et al. Revisited phase diagram on charge instability and lattice symmetry breaking in the organic ferroelectric TTF-QCl 4 . Physical Review B 98, 054103 (2018).

22 Kobayashi, K. et al. Electronic Ferroelectricity in a Molecular Crystal with Large Polarization Directing Antiparallel to Ionic Displacement. Physical Review Letters 108, 237601 (2012).

23 Spin-Crossover Materials: Properties and Application (ed. Halcrow, M. A.) John Wiley \& Sons, Ltd, UK, 2013).

$24 \mathrm{Li}$, L. et al. High pyroelectric performance due to ferroelectric-antiferroelectric transition near room temperature. Journal of Materials Chemistry C 8, 7820-7827 (2020).

25 Wu, S.-Q. et al. Macroscopic Polarization Change via Electron Transfer in a Valence Tautomeric Cobalt Complex. Nature Communications 11, 1992 (2020).

26 Scott, J. F. Applications of Modern Ferroelectrics. Science 315, 954-959 (2007).

27 A century of ferroelectricity. Nature Materials 19, 129-129 (2020).

28 Yang, M.-M. et al. Piezoelectric and pyroelectric effects induced by interface polar symmetry. Nature 584, 377-381 (2020).

29 Horiuchi, S. \& Tokura, Y. Organic ferroelectrics. Nature Materials 7, 357-366 (2008). 
30 Kanegawa, S. et al. Directional Electron Transfer in Crystals of [CrCo] Dinuclear Complexes Achieved by Chirality-Assisted Preparative Method. Journal of the American Chemical Society 138, 14170-14173 (2016).

31 Floquet, S. et al. Spin crossover of ferric complexes with catecholate derivatives. Singlecrystal X-ray structure, Magnetic and Mössbauer investigations. Dalton Transactions, 1734-1742 (2005).

32 Simaan, A. J., Boillot, M.-L., Rivière, E., Boussac, A. \& Girerd, J.-J. A Two-Step Spin Crossover in [(TPA)Fe ${ }^{\mathrm{III}}$ (cat)]BPh 4 . Angewandte Chemie International Edition 39, 196198 (2000).

33 Tao, J., Maruyama, H. \& Sato, O. Valence Tautomeric Transitions with Thermal Hysteresis around Room Temperature and Photoinduced Effects Observed in a Cobalt-Tetraoxolene Complex. Journal of the American Chemical Society 128, 17901791 (2006).

34 Schmidt, R. D., Shultz, D. A. \& Martin, J. D. Magnetic Bistability in a Cobalt Bis(dioxolene) Complex: Long-Lived Photoinduced Valence Tautomerism. Inorganic Chemistry 49, 3162-3168 (2010).

35 Baker, M. L. et al. K- and L-edge X-ray absorption spectroscopy (XAS) and resonant inelastic X-ray scattering (RIXS) determination of differential orbital covalency (DOC) of transition metal sites. Coordination Chemistry Reviews 345, 182-208 (2017).

36 Dei, A., Gatteschi, D., Sangregorio, C. \& Sorace, L. Quinonoid Metal Complexes: Toward Molecular Switches. Accounts of Chemical Research 37, 827-835 (2004).

37 Simaan, A. J. et al. Electronic, Vibrational, and Structural Properties of a Spin-Crossover Catecholato-Iron System in the Solid State: Theoretical Study of the Electronic Nature of the Doublet and Sextet States. Chemistry - A European Journal 11, 1779-1793 (2005).

38 Kepler, R. G. Ferroelectric, pyroelectric and piezoelectric properties of poly(vinylidene fluoride). In Ferroelectric Polymers: Chemistry, Physics and Applications (ed. Nalwa, H. S.) (Marcel Dekker, Inc, New York, 2005).

39 Girerd, J. J., Boillot, M. L., Blain, G. \& Rivière, E. An EPR investigation of the electronic structure of pseudo-octahedral and spin crossover catecholato-iron(III) complexes in the low-spin state. Inorganica Chimica Acta 361, 4012-4016 (2008). 
40 Westre, T. E. et al. A Multiplet Analysis of Fe K-Edge 1s $\rightarrow$ 3d Pre-Edge Features of Iron Complexes. Journal of the American Chemical Society 119, 6297-6314 (1997).

41 Wilson, S. A. et al. Iron L-Edge X-ray Absorption Spectroscopy of Oxy-Picket Fence Porphyrin: Experimental Insight into Fe-O2 Bonding. Journal of the American Chemical Society 135, 1124-1136 (2013).

42 Wasinger, E. C. et al. X-ray Absorption Spectroscopic Investigation of the Resting Ferrous and Cosubstrate-Bound Active Sites of Phenylalanine Hydroxylase. Biochemistry 41, 6211-6217 (2002).

43 Dei, A., Gatteschi, D., Pardi, L. \& Russo, U. Tetraoxolene radical stabilization by the interaction with transition-metal ions. Inorganic Chemistry 30, 2589-2594 (1991).

44 Li, G.-L. et al. Influence of Intermolecular Interactions on Valence Tautomeric Behaviors in Two Polymorphic Dinuclear Cobalt Complexes. Chemistry - A European Journal 22, 17130-17135 (2016).

45 Tait, A. M., Busch, D. H. \& Curtis, N. F. 5,5,7,12,12,14-Hexamethyl-1,4,8,11Tetraazacyclo-Tetradecane $\left(5,5,7,12,12,14-\mathrm{Me}_{6}[14]\right.$ Ane-1,4,8,11-N 4$)$ complexes. Inorg. Synth. 18, 10-17 (1978).

46 Sokaras, D. et al. A seven-crystal Johann-type hard x-ray spectrometer at the Stanford Synchrotron Radiation Lightsource. Review of Scientific Instruments 84, 053102 (2013).

47 Lubomirsky, I. \& Stafsudd, O. Invited Review Article: Practical guide for pyroelectric measurements. Review of Scientific Instruments 83, 051101 (2012). 
(a)

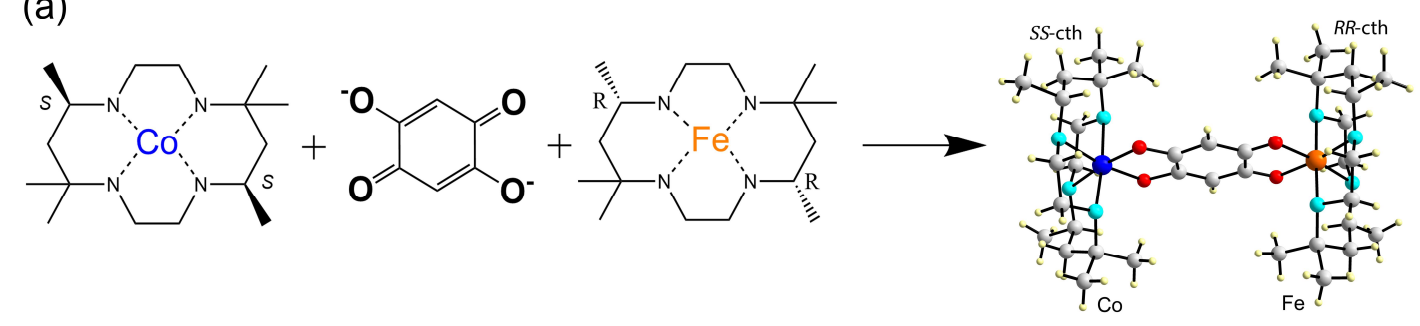

(b)

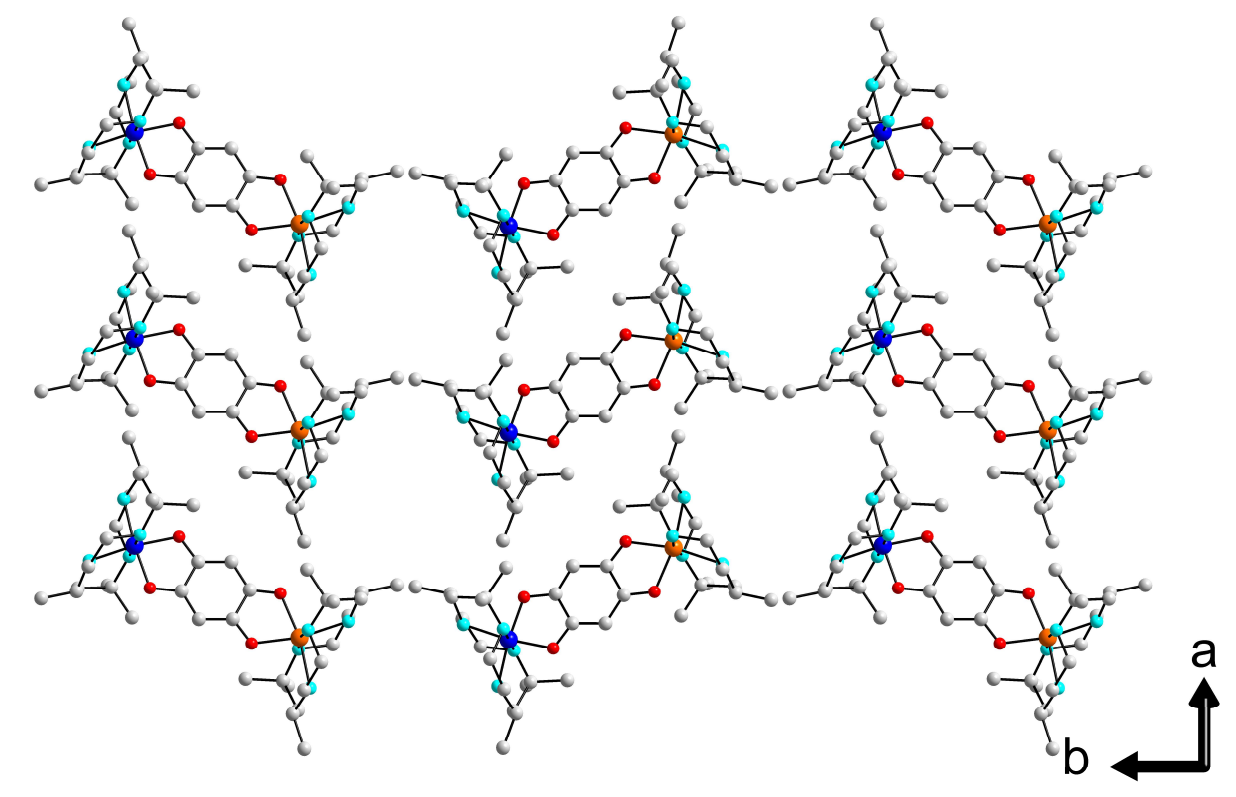

Fig. 1 | (a) Synthetic strategy toward the heterometallic dinuclear complex 1(PF6)3 [Fe(orange), $\mathrm{Co}$ (blue), $\mathrm{O}\left(\right.$ red), $\mathrm{C}$ (gray)]; $\mathrm{H}$ atoms are omitted for clarity. (b) Crystal packing of $\mathbf{1}\left(\mathbf{P F}_{\mathbf{6}} \mathbf{3}\right.$ at 130 $\mathrm{K}$ along the crystallographic c-axis. 

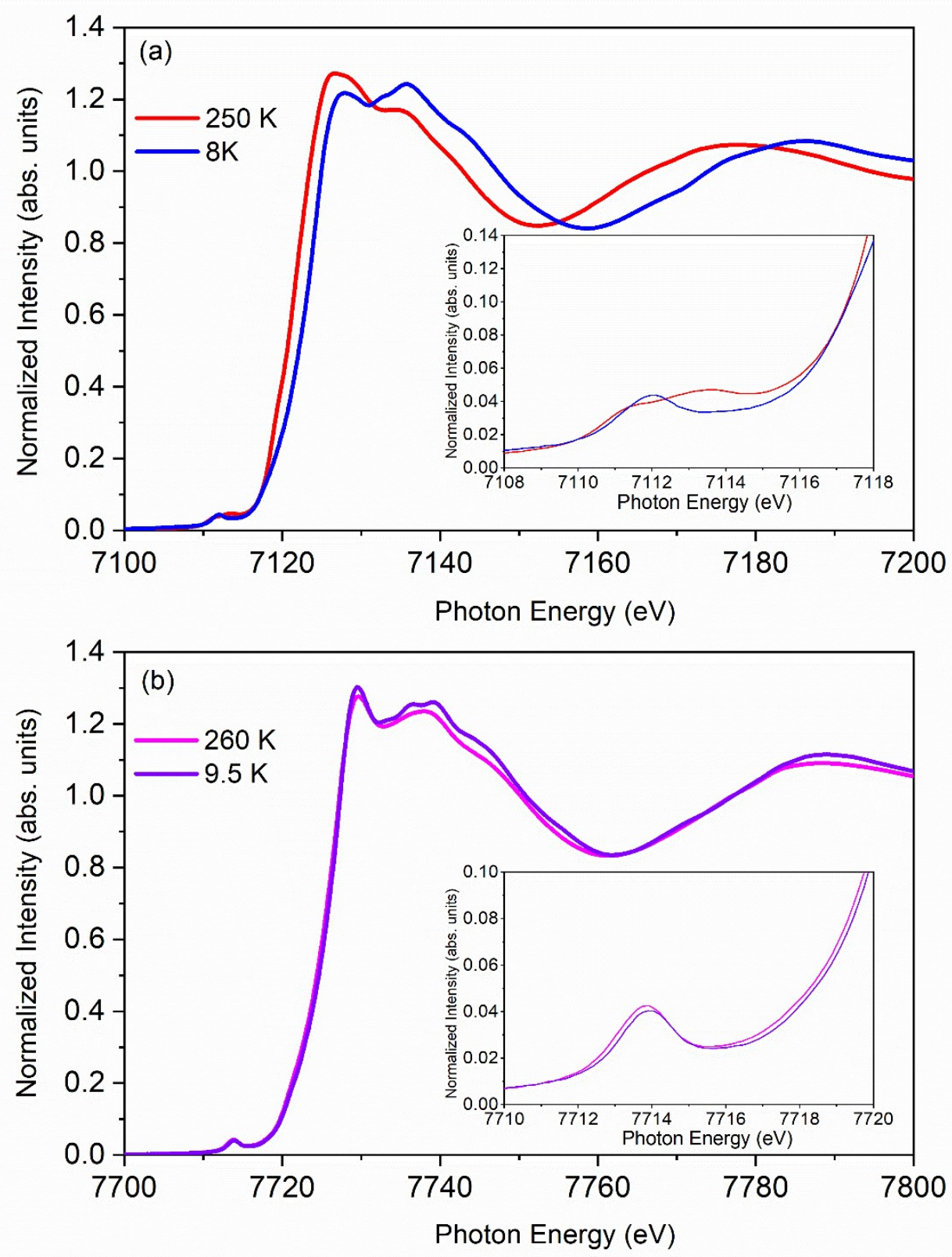

Fig. 2 | (a) Temperature-dependent Fe K-edge X-ray absorption spectroscopy (XAS) data for 1(PF6)3. Inset- Fe pre-edge XAS data. (b) Co K-edge XAS data. Inset- Co pre-edge XAS data. 


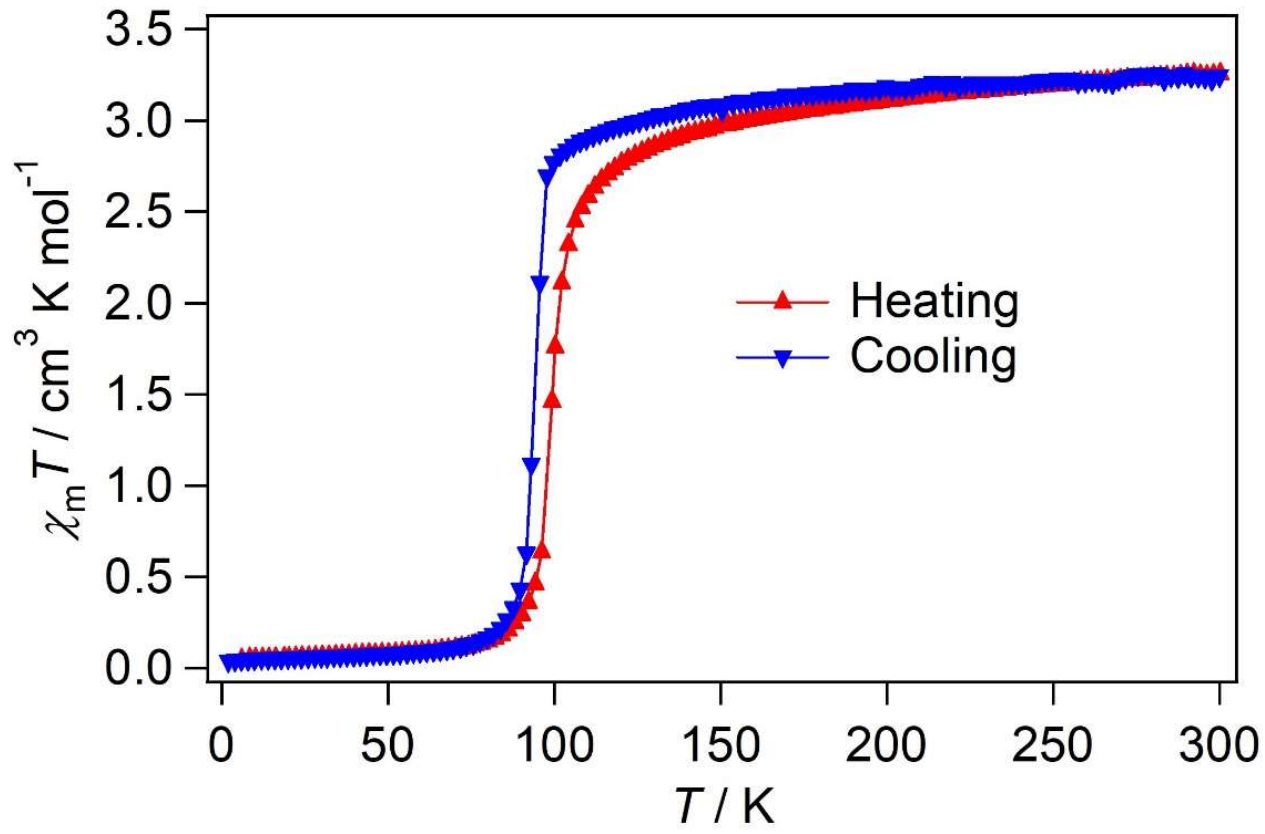

Fig. 3 Temperature dependence of magnetic susceptibilities displayed as a plot of $\chi_{\mathrm{m}} T$ vs. $T$. Data were collected on heating and cooling modes with a temperature sweep rate of $2.5 \mathrm{~K} / \mathrm{min}$. 

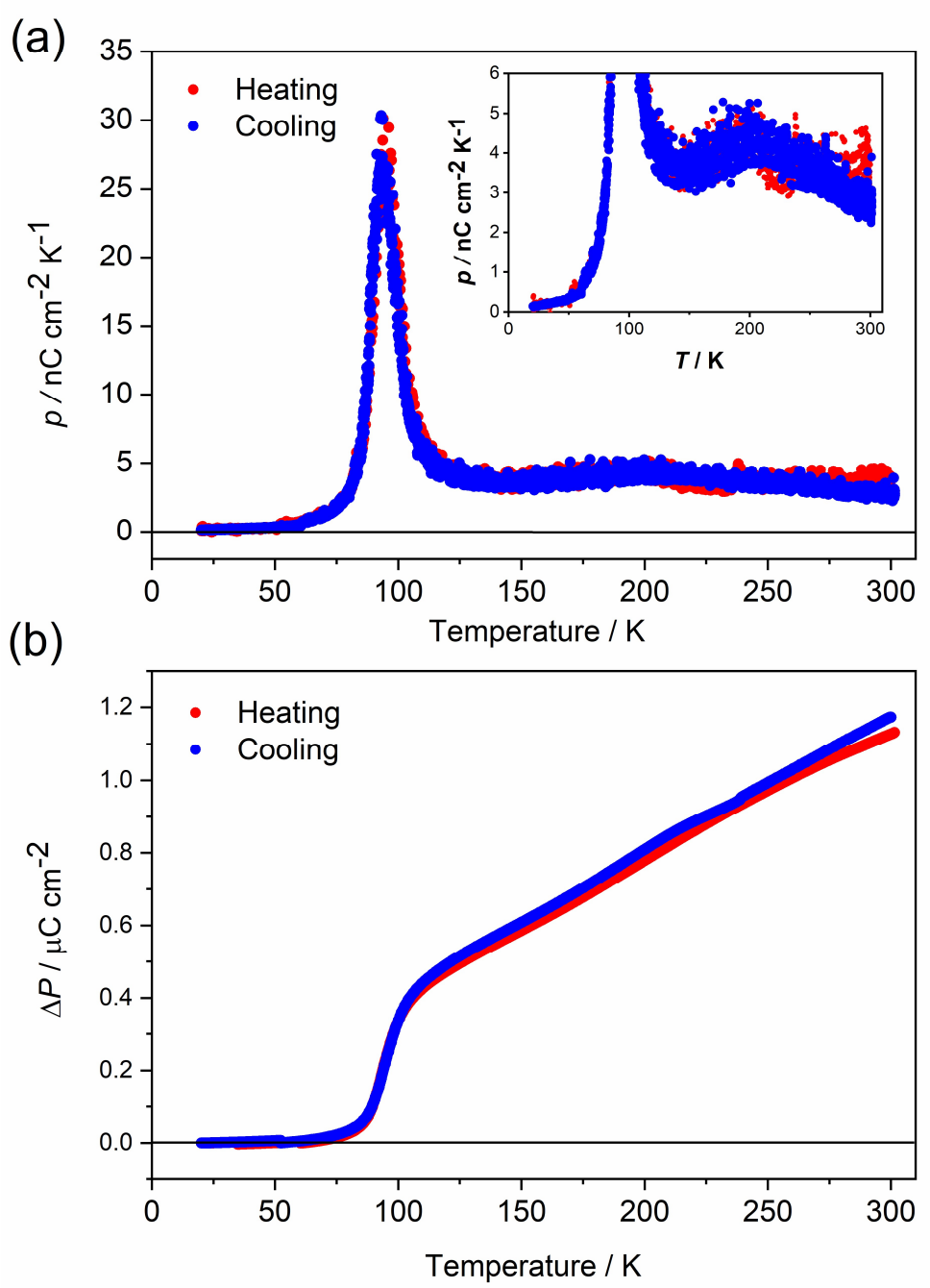

Fig. 4 | (a) Temperature dependence of the pyroelectric coefficient for $\mathbf{1}\left(\mathbf{P F}_{6}\right) \mathbf{3}$. Pyroelectric coefficients are almost constant at approximately $2.4-5.0 \mathrm{nC} \mathrm{cm}^{-2} \mathrm{~K}^{-1}$ between 300 and $120 \mathrm{~K}$. Sharp peaks are obtained on both cooling and heating modes at ca. $90 \mathrm{~K}$. These are consistent with the transition temperature observed in the magnetic measurements. No pyroelectric current is detected below the phase transition temperature. Data were collected with a temperature sweep rate of $5 \mathrm{~K} / \mathrm{min}$. Inset: expansion between $0-6 \mathrm{nC} \mathrm{cm}^{-2} \mathrm{~K}^{-1}$. (b) Temperature-dependent polarization change $(\Delta P)$ plot with respect to the lowest temperature data $(20 \mathrm{~K})$ for $\mathbf{1}\left(\mathbf{P F}_{6}\right)_{3}$. The calculated polarization change is ca. $1.15 \mu \mathrm{C} \mathrm{cm}^{-2}$ at $300 \mathrm{~K}$. Data were collected on heating and cooling modes with a temperature sweep rate of $5 \mathrm{~K} / \mathrm{min}$. 

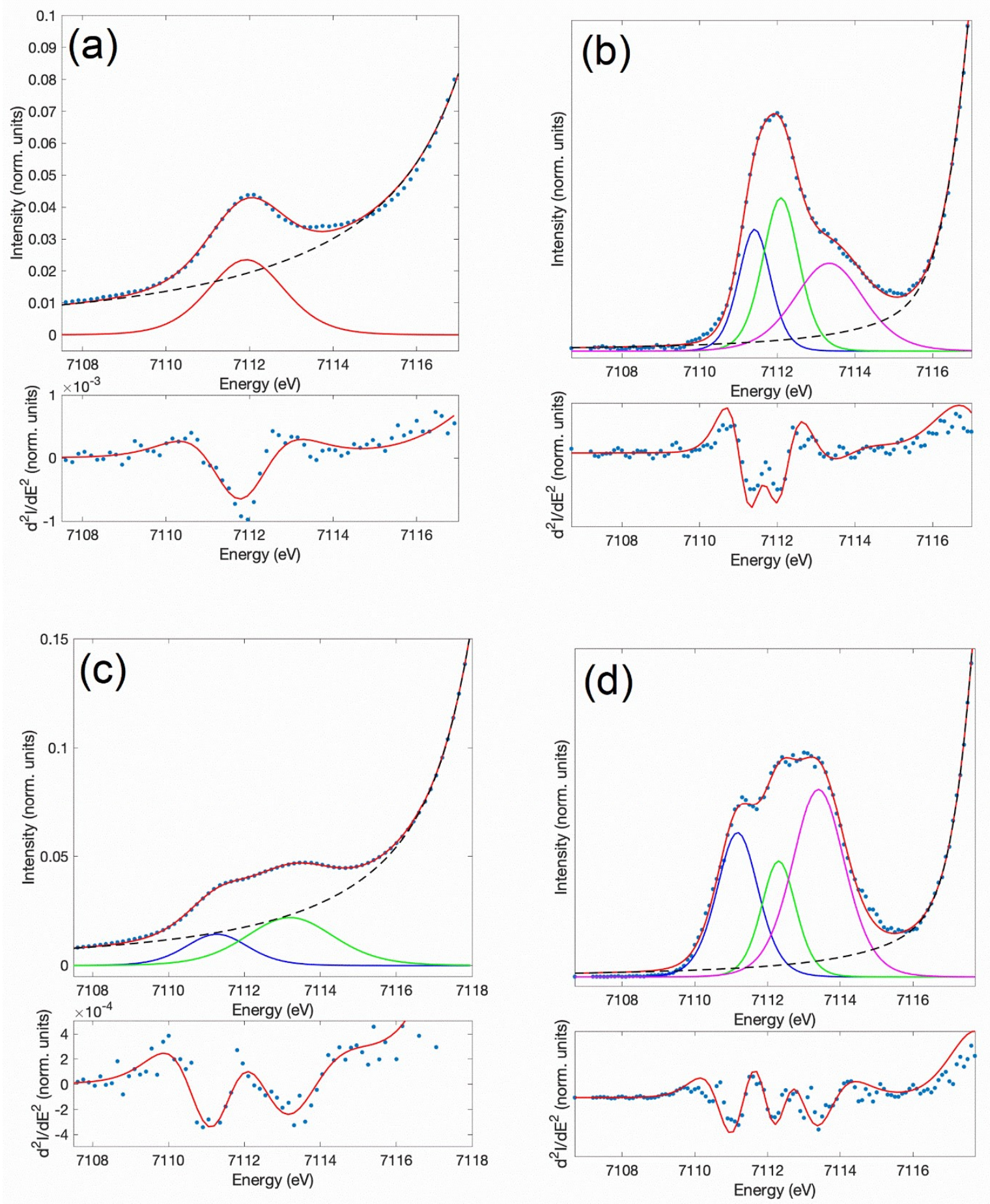

Figure 5 | (a) Upper figure: Fe-XANES pre-edge measured at $8 \mathrm{~K}$ (blue circles), fit to the rising edge (broken black line) and total fit (solid red line). Lower figure: second derivative of FeXANES measured at $8 \mathrm{~K}$ (blue circles) with related fit (solid red line). (b) Upper figure: Fe HERFD-XANES measured at $8 \mathrm{~K}$ (blue circles), fit to the rising edge (broken black line), 
individual peak fits (solid lines, blue, green, magenta) and total fit (solid red line). Lower figure: second derivative of Fe HERFD-XANES measured at $8 \mathrm{~K}$ (blue circles) with related fit (solid red line). (c) Upper figure: Fe-XANES pre-edge measured at $250 \mathrm{~K}$ (blue circles), fit to the rising edge (broken black line), individual peak fits (solid lines, blue, green) and total fit (solid red line). Lower figure: second derivative of Fe-XANES measured at $250 \mathrm{~K}$ (blue circles) with related fit (solid red line). (d) Upper figure: Fe HERFD-XANES measured at $250 \mathrm{~K}$ (blue circles), fit to the rising edge (broken black line), individual peak fits (solid lines, blue, green, magenta) and total fit (solid red line). Lower figure: second derivative of Fe HERFD-XANES measured at $250 \mathrm{~K}$ (blue circles) with related fit (solid red line). 

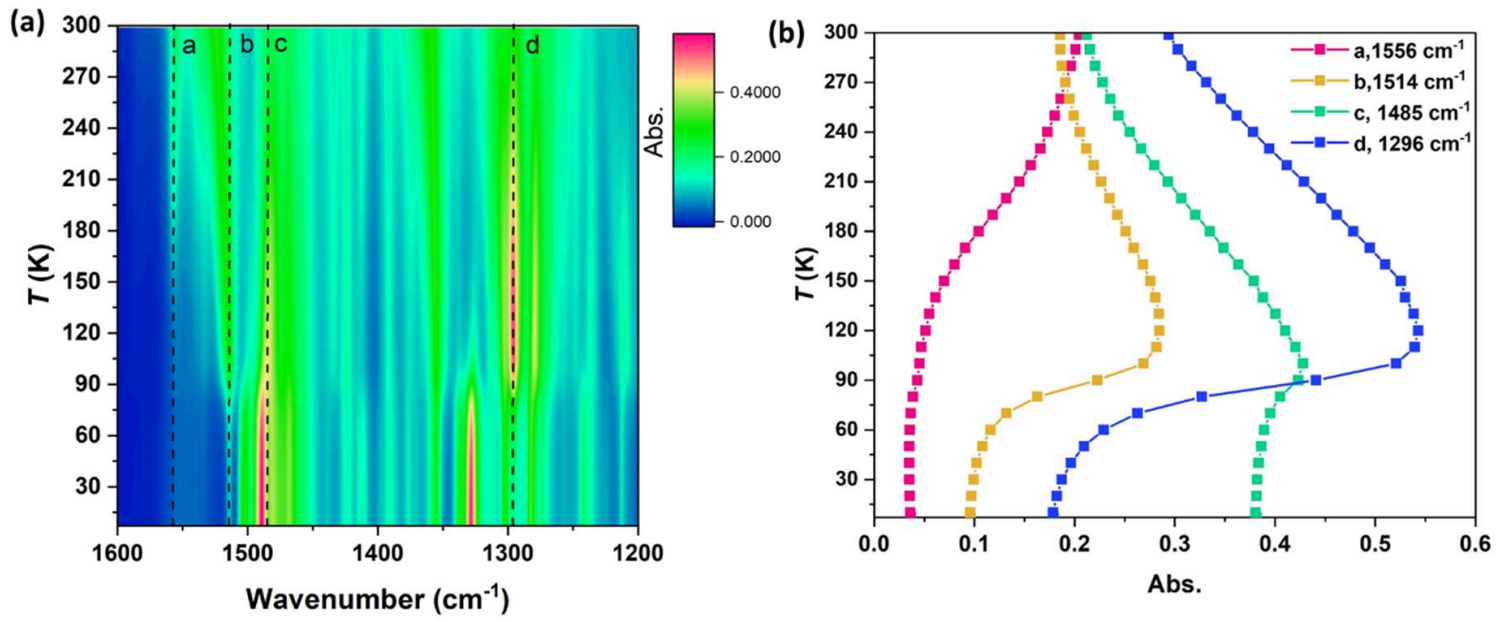

Fig. 6 | (a) 2D color map of the variable-temperature IR absorption spectra for the range of 1200 $-1600 \mathrm{~cm}^{-1}$ for the temperature range of $300 \mathrm{~K}-10 \mathrm{~K}$. Dashed lines represent the characteristic absorption bands. Abrupt change in absorbance at $1514 \mathrm{~cm}^{-1}$ (line b) and $1296 \mathrm{~cm}^{-1}$ (line d) is observed at approximately $90 \mathrm{~K}$ (Supplementary Fig.10), which is consistent with the spin transition temperature. Even above spin transition temperature, a gradual change in absorbance is clearly detected. Absorbance at $1556 \mathrm{~cm}^{-1}$ (line a) and $1485 \mathrm{~cm}^{-1}$ (line c) gradually increases and decreases with increasing temperature, respectively. Absorbance at $1556 \mathrm{~cm}^{-1}$ and $1485 \mathrm{~cm}^{-1}$ is assignable to that of $\mathrm{dhbq}^{2-}$ and $\mathrm{dhbq}^{3-}$, respectively, suggesting that the increase of the population of $\left[\mathrm{Fe}^{2+} \mathrm{HS}^{-} \mathrm{dhbq}^{2-}-\mathrm{Co}^{3+} \mathrm{LS}\right]$ state on the increment of temperature. (b) Temperature-dependent IR absorptions of selected wavenumbers shown in panel (a). 


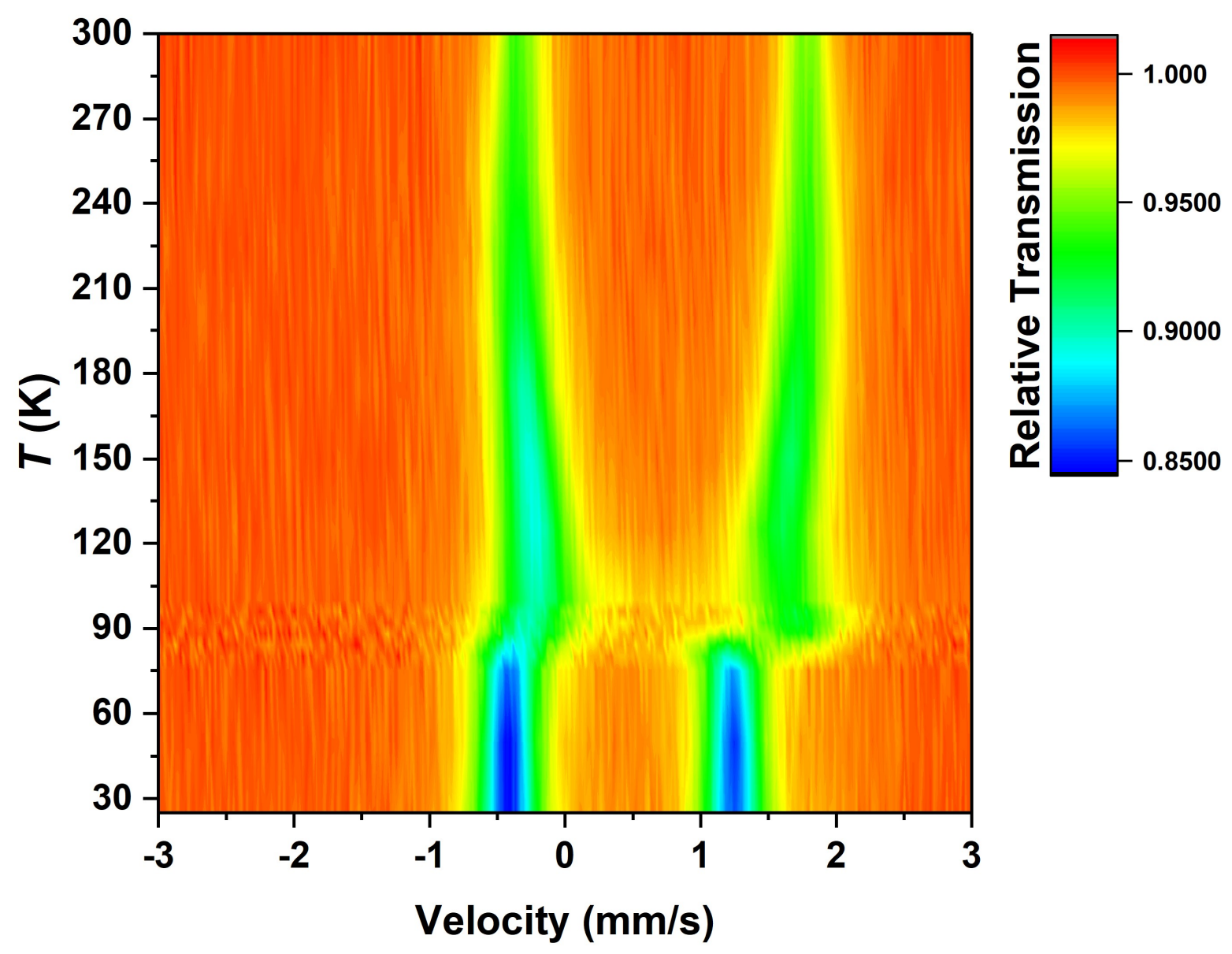

Fig. $7 \mid$ Temperature-dependent Mössbauer spectra of $\mathbf{1}\left(\mathbf{P F}_{\mathbf{6}}\right)_{\mathbf{3}}$ between the temperature range from 300 to $25 \mathrm{~K}$. Spin transition is observed at approximately $90 \mathrm{~K}$. Upon heating above the spin transition temperature, the quadrupole splitting (QS) value is getting larger, which suggests that the contribution of the $\left[\mathrm{Fe}^{2+} \mathrm{HS}^{-}-\mathrm{dhbq}^{2-}-\mathrm{Co}^{3+} \mathrm{LS}\right]$ state increases with temperature at the hightemperature phase. 


\section{Figures}

(a)

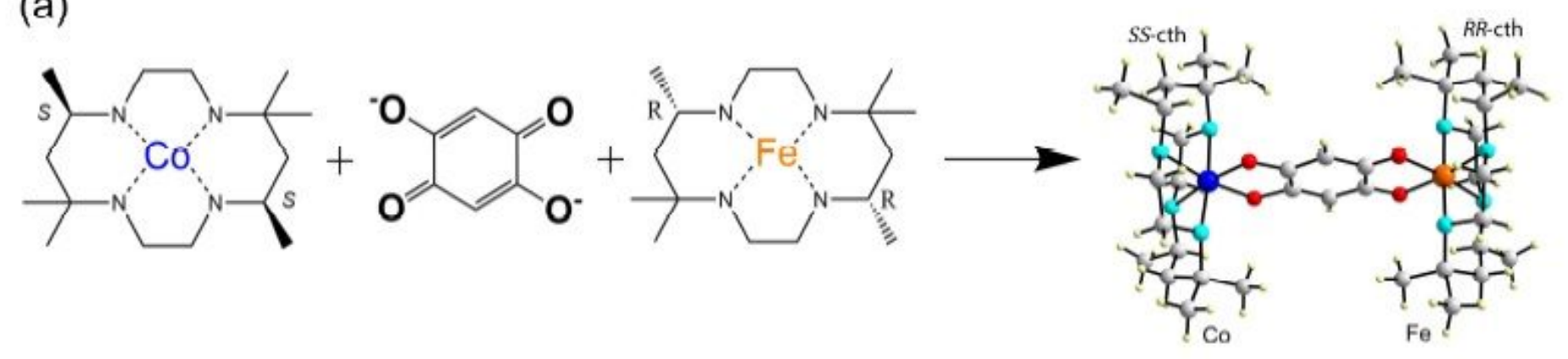

(b)

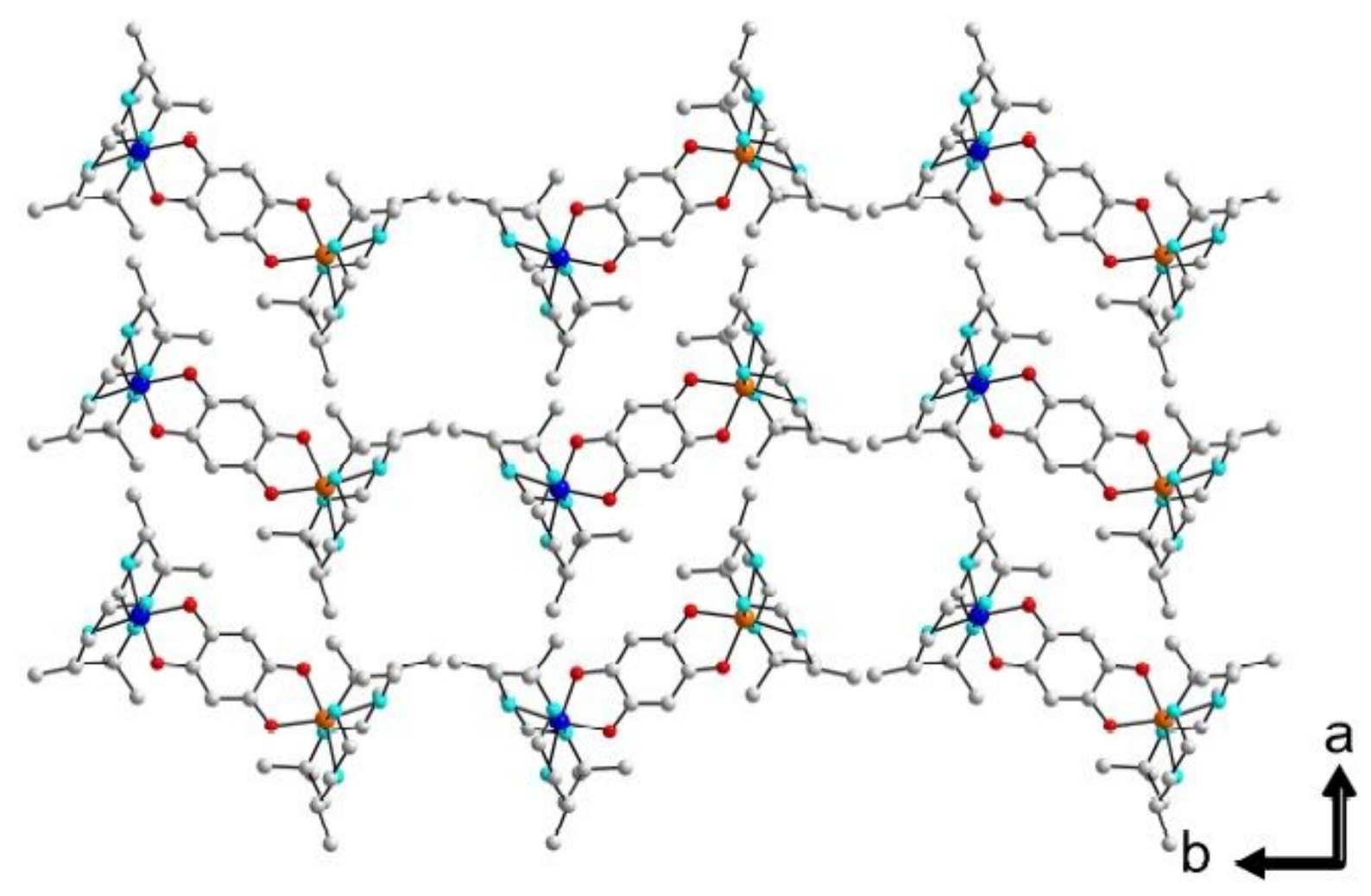

\section{Figure 1}

(a) Synthetic strategy toward the heterometallic dinuclear complex 1(PF6)3 [Fe(orange),Co(blue), O(red), $\mathrm{C}$ (gray)]; $\mathrm{H}$ atoms are omitted for clarity. (b) Crystal packing of 1 (PF6) 3 at $130 \mathrm{~K}$ along the crystallographic c-axis. 

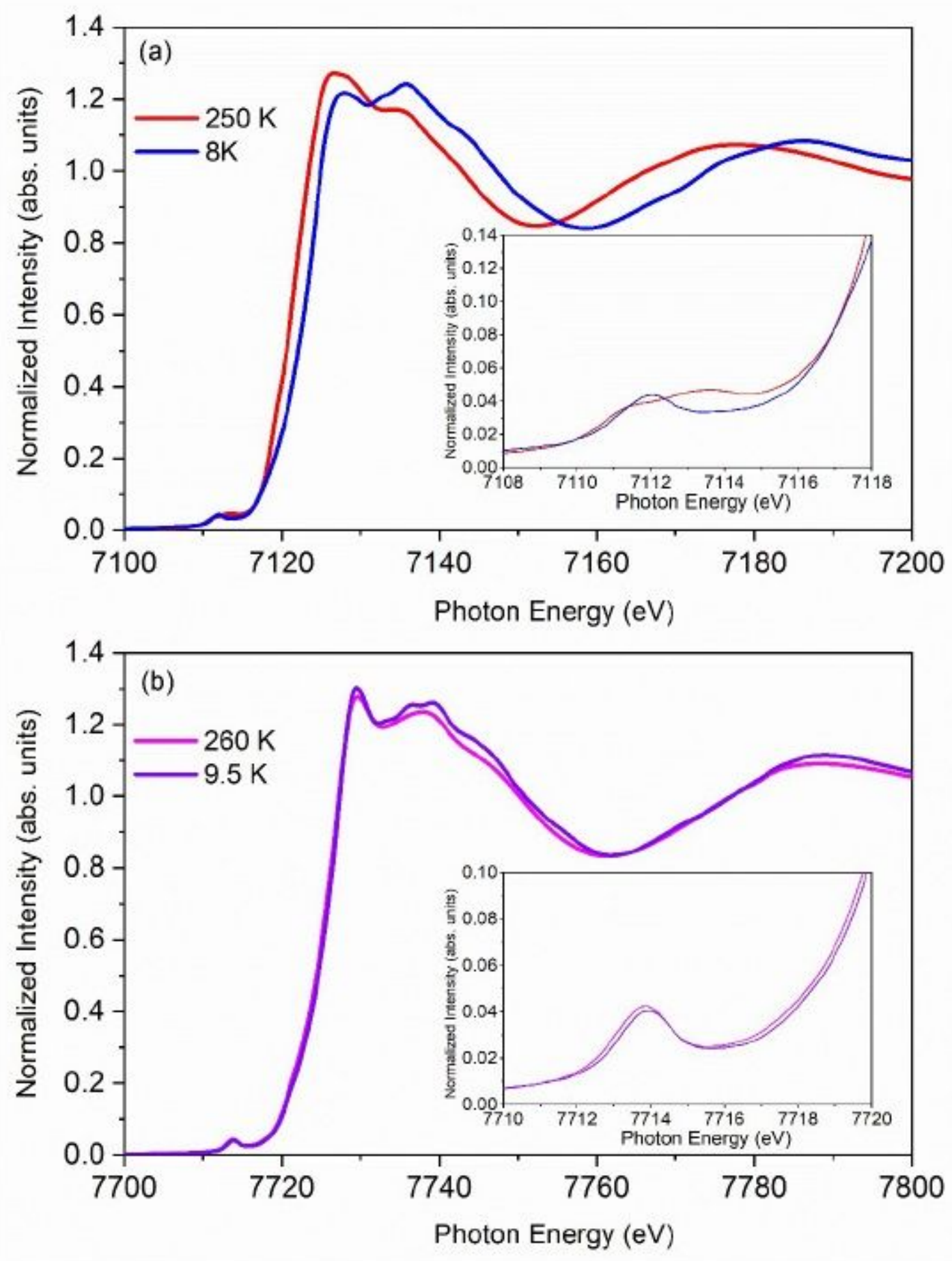

Figure 2

(a) Temperature-dependent Fe K-edge X-ray absorption spectroscopy (XAS) data for 1(PF6)3. Inset- Fe pre-edge XAS data. (b) Co K-edge XAS data. Inset- Co pre-edge XAS data. 


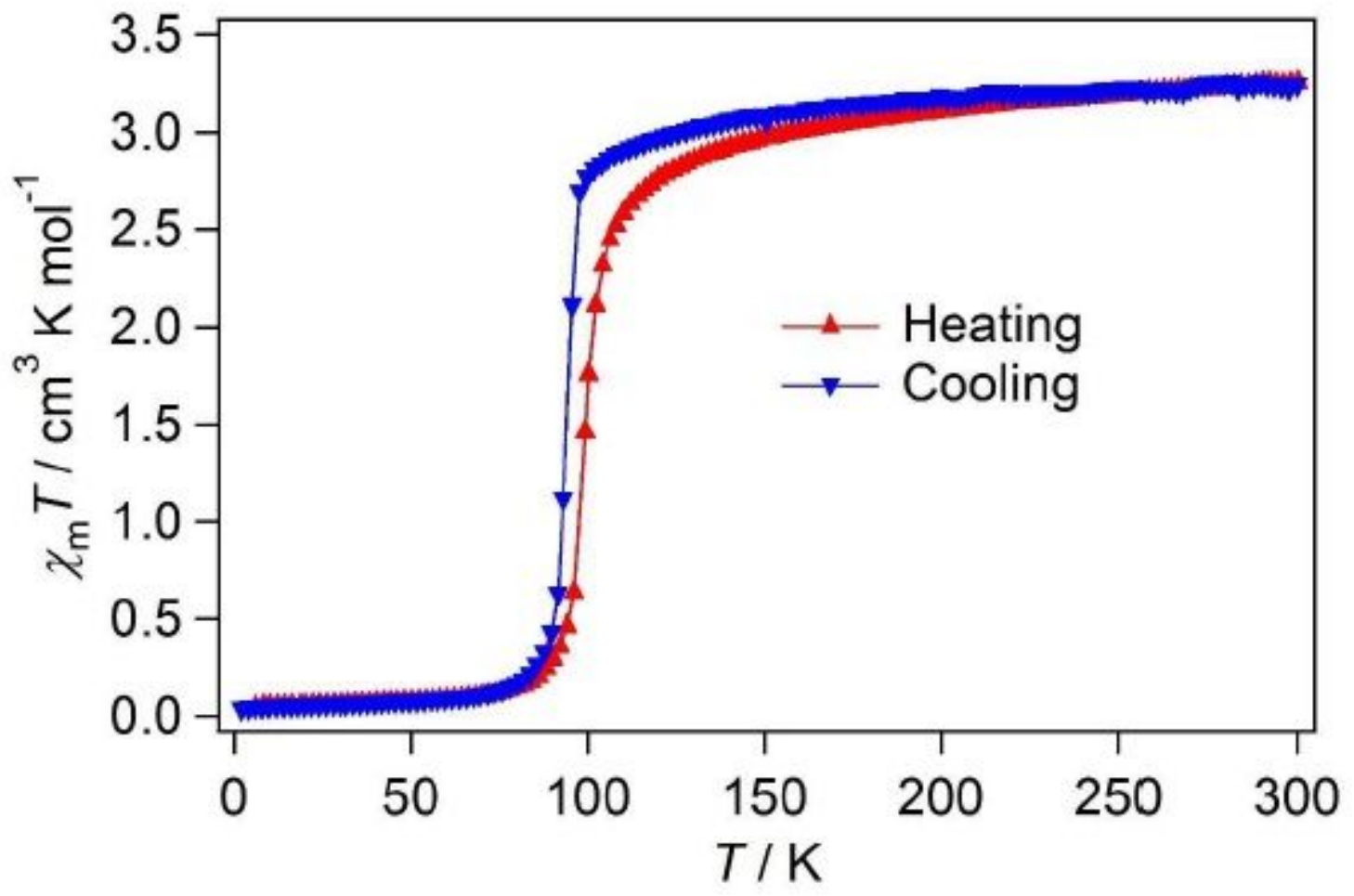

Figure 3

Temperature dependence of magnetic susceptibilities displayed as a plot of ymT vs. T. Data were collected on heating and cooling modes with a temperature sweep rate of $2.5 \mathrm{~K} / \mathrm{min}$. 

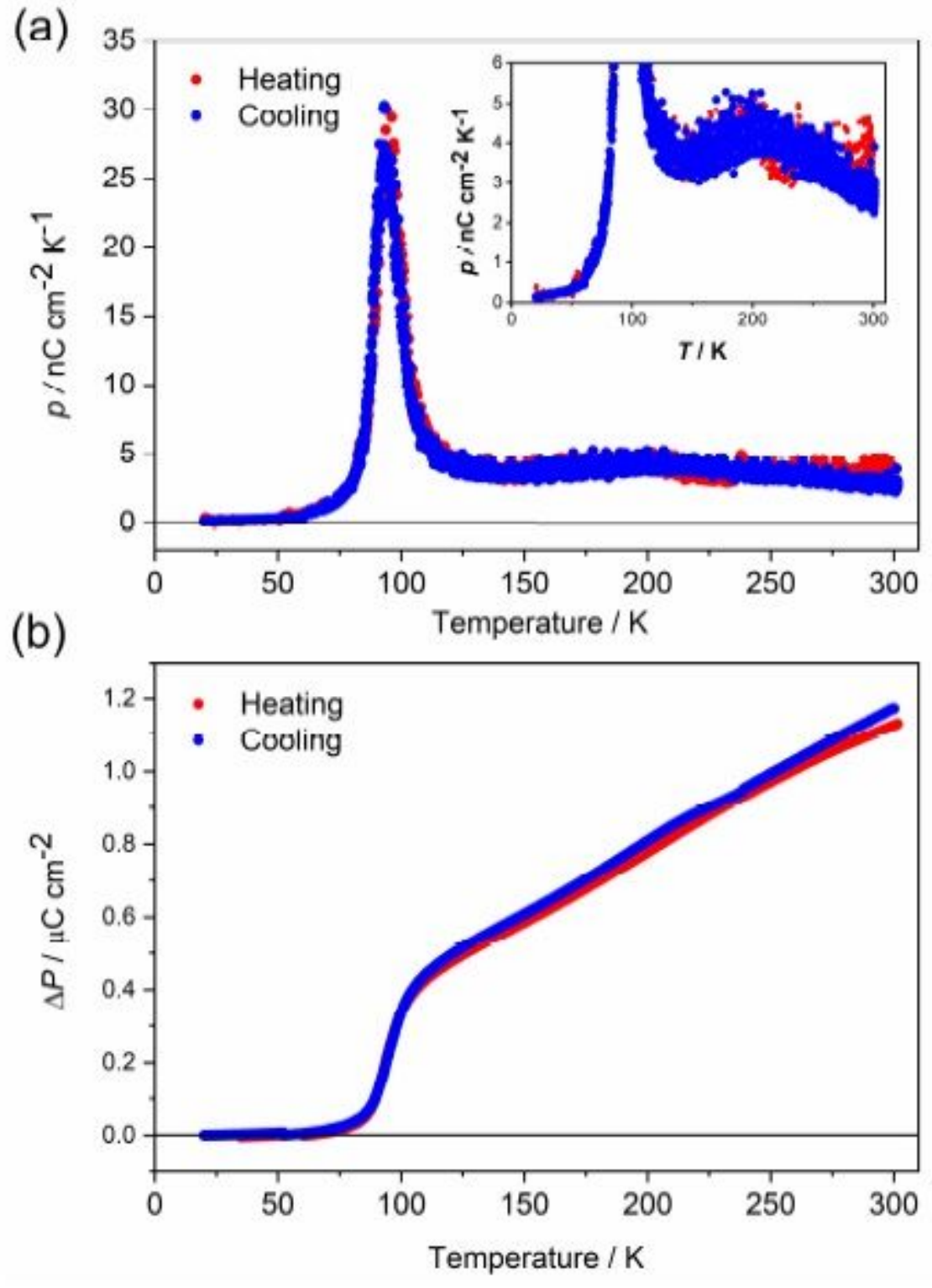

Figure 4

(a) Temperature dependence of the pyroelectric coefficient for 1(PF6)3. Pyroelectric coefficients are almost constant at approximately $2.4-5.0 \mathrm{nC} \mathrm{cm}-2 \mathrm{~K}-1$ between 300 and $120 \mathrm{~K}$. Sharp peaks are obtained on both cooling and heating modes at ca. $90 \mathrm{~K}$. These are consistent with the transition temperature observed in the magnetic measurements. No pyroelectric current is detected below the phase transition temperature. Data were collected with a temperature sweep rate of $5 \mathrm{~K} / \mathrm{min}$. Inset: expansion between 0-6 $\mathrm{nC} \mathrm{cm}-2 \mathrm{~K}-1$. (b) Temperature-dependent polarization change $(\Delta \mathrm{P})$ plot with respect to the lowest temperature data $(20 \mathrm{~K})$ for 1 (PF6)3. The calculated polarization change is ca. $1.15 \mathrm{yC} \mathrm{cm}-2$ at $300 \mathrm{~K}$. Data were collected on heating and cooling modes with a temperature sweep rate of $5 \mathrm{~K} / \mathrm{min}$. 

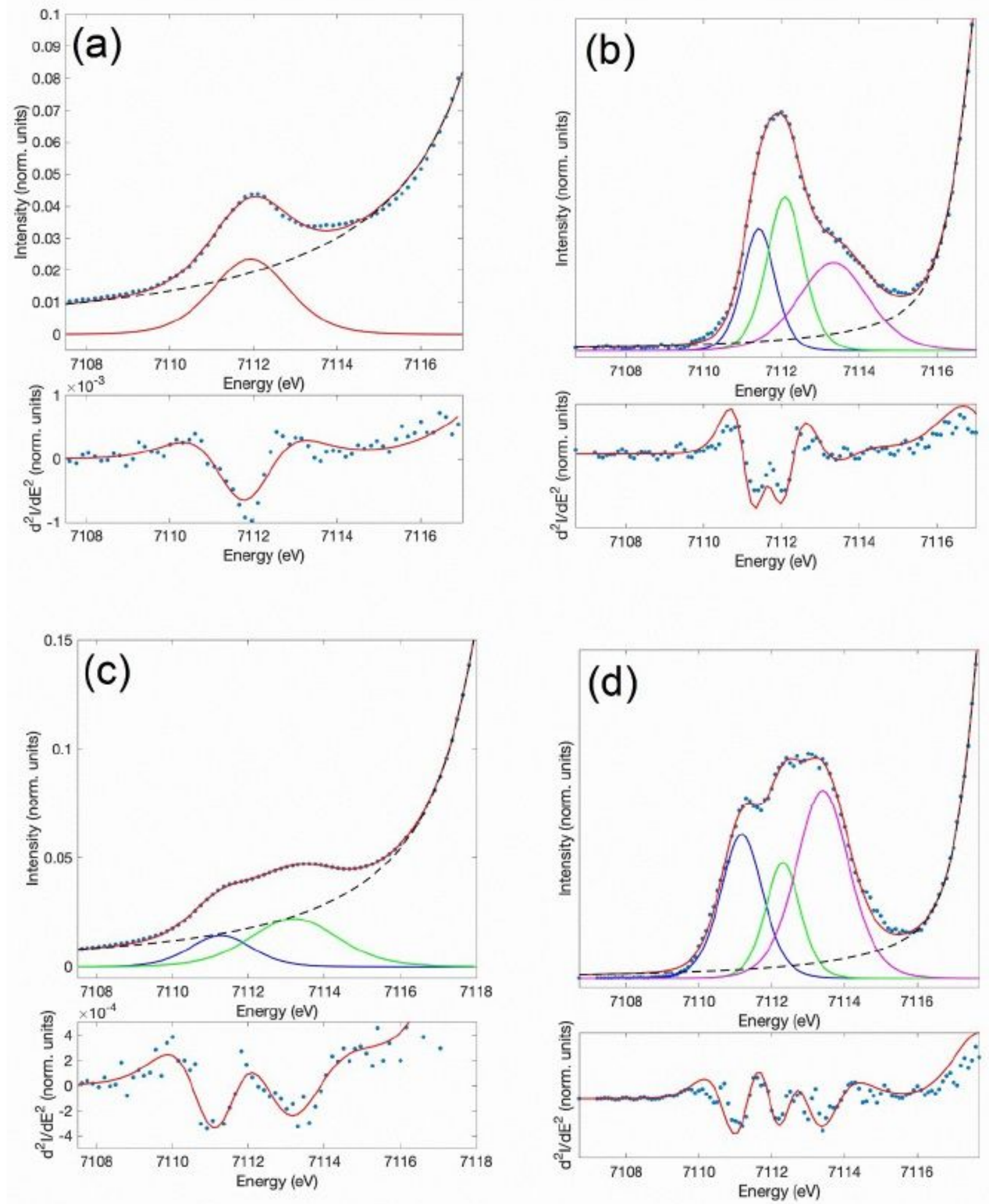

\section{Figure 5}

(a) Upper figure: Fe-XANES pre-edge measured at $8 \mathrm{~K}$ (blue circles), fit to the rising edge (broken black line) and total fit (solid red line). Lower figure: second derivative of Fe-XANES measured at $8 \mathrm{~K}$ (blue circles) with related fit (solid red line). (b) Upper figure: Fe HERFD-XANES measured at $8 \mathrm{~K}$ (blue circles), fit to the rising edge (broken black line), individual peak fits (solid lines, blue, green, magenta) and total fit (solid red line). Lower figure: second derivative of Fe HERFD-XANES measured at $8 \mathrm{~K}$ (blue circles) with 
related fit (solid red line). (c) Upper figure: Fe-XANES pre-edge measured at $250 \mathrm{~K}$ (blue circles), fit to the rising edge (broken black line), individual peak fits (solid lines, blue, green) and total fit (solid red line). Lower figure: second derivative of Fe-XANES measured at $250 \mathrm{~K}$ (blue circles) with related fit (solid red line). (d) Upper figure: Fe HERFD-XANES measured at $250 \mathrm{~K}$ (blue circles), fit to the rising edge (broken black line), individual peak fits (solid lines, blue, green, magenta) and total fit (solid red line). Lower figure: second derivative of Fe HERFD-XANES measured at $250 \mathrm{~K}$ (blue circles) with related fit (solid red line).
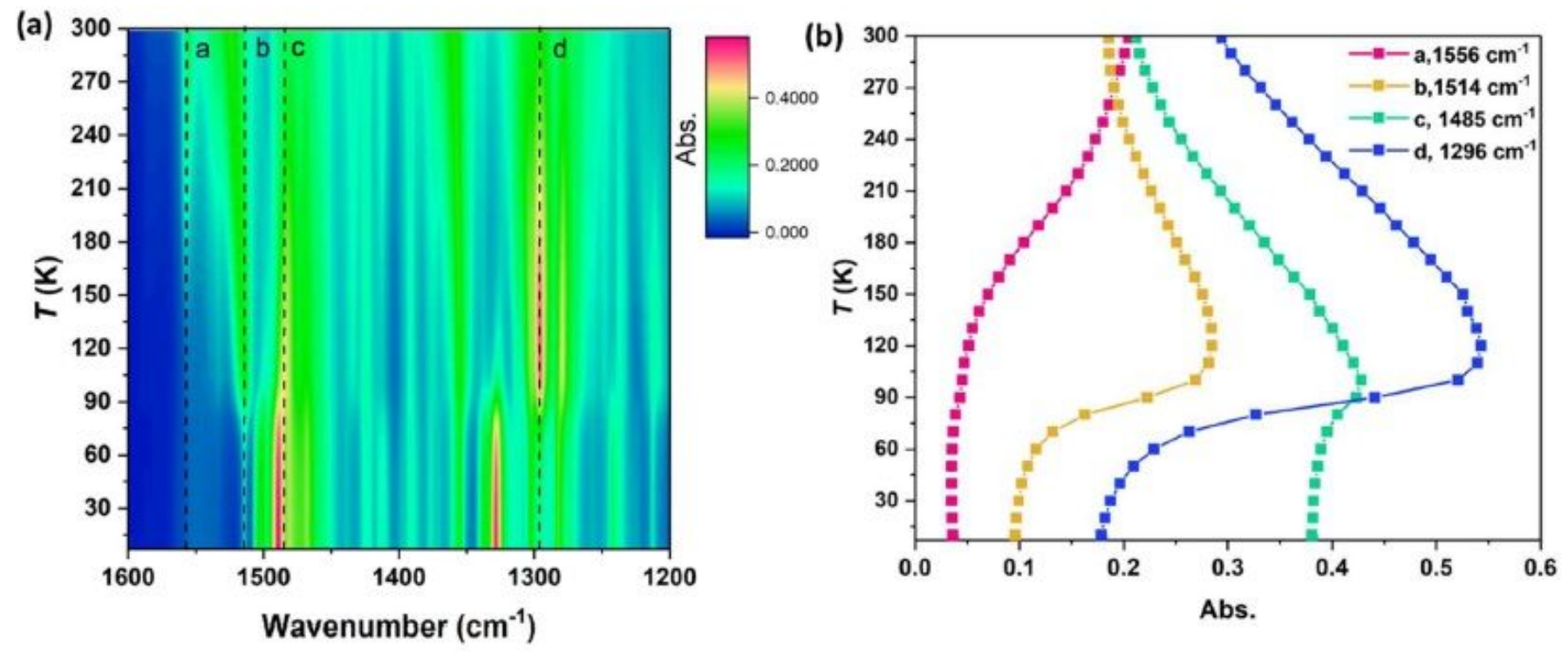

Figure 6

(a) 2D color map of the variable-temperature IR absorption spectra for the range of $1200-1600 \mathrm{~cm}-1$ for the temperature range of $300 \mathrm{~K}-10 \mathrm{~K}$. Dashed lines represent the characteristic absorption bands. Abrupt change in absorbance at $1514 \mathrm{~cm}-1$ (line b) and $1296 \mathrm{~cm}-1$ (line d) is observed at approximately $90 \mathrm{~K}$ (Supplementary Fig.10), which is consistent with the spin transition temperature. Even above spin transition temperature, a gradual change in absorbance is clearly detected. Absorbance at $1556 \mathrm{~cm}-1$ (line a) and $1485 \mathrm{~cm}-1$ (line c) gradually increases and decreases with increasing temperature, respectively. Absorbance at $1556 \mathrm{~cm}-1$ and $1485 \mathrm{~cm}-1$ is assignable to that of dhbq2- and dhbq3-, respectively, suggesting that the increase of the population of [Fe2+HS-dhbq2--Co3+LS] state on the increment of temperature. (b) Temperature-dependent IR absorptions of selected wavenumbers shown in panel (a). 


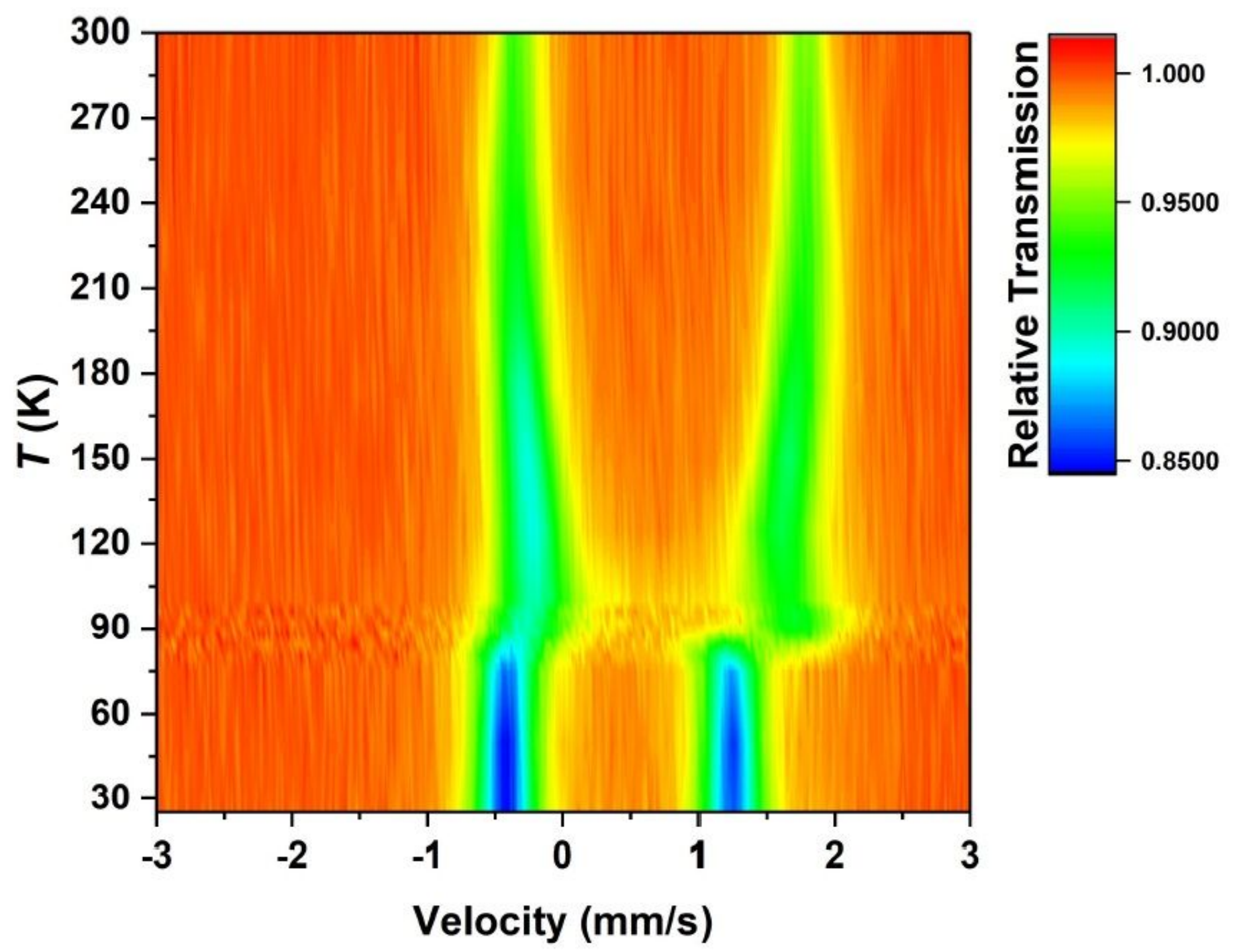

Figure 7

Temperature-dependent Mössbauer spectra of 1(PF6)3 between the temperature range from 300 to $25 \mathrm{~K}$. Spin transition is observed at approximately $90 \mathrm{~K}$. Upon heating above the spin transition temperature, the quadrupole splitting (QS) value is getting larger, which suggests that the contribution of the [Fe2+ HS-dhbq2--Co3+LS] state increases with temperature at the hightemperature phase.

\section{Supplementary Files}

This is a list of supplementary files associated with this preprint. Click to download.

- FeCo60K.cif

- FeCo100K.cif

- FeCo150K.cif

- FeCo200K.cif 
- FeCo250K.cif

- FeCo300K.cif

- CoZn250K.cif

- CoZn100K.cif

- Supp.info.210211A.pdf 